\title{
DECISION AND SYSTEMS ANALYSIS FOR \\ UNDERGROUND STORAGE TANK WASTE RETRIEVAL SYSTEMS AND \\ TANK WASTE REMEDIATION SYSTEM*
}

\author{
Mr. Dennis A. Bitz, P.E. \\ Independent Consultant \\ Dr. Dennis L. Berry \\ Sandia National Laboratories \\ Albuquerque, NM 87185 \\ Dr. Leslie J. Jardine \\ Lawrence Livermore National Laboratory \\ Livermore, CA 94551-9900 \\ MASTER
}

DASTRIBUTION OF THIS DOCUMENT IS UNLIMITED

yr

"This work was supported by the U.S. Department of Energy and performed at Sandia National Laboratories under contract DE-AC04-94AL85000 and at Lawrence Livermore National Laboratory under contract W-7405-Eng-48. Direct funding for this work was received from the DOE Environmental Restoration and Waste Management Office of Technology Development as part of the Underground Storage Tank Integrated Demonstration Program. Specifical1y, Lawrence Livermore was supported by Technical Task Plan (TTP) SF2212-02, "UST Retrieval, Transport, Storage Technology Concepts Development: Independent Review Group Activities," and Sandia was supported by TTP AL 2212-03, "UST Retrieval, Transport, and Storage Concepts." 


\section{CONTENTS}

Page

1.0 EXECUTIVE SUMMARY . . . . . . . . . . . . . . . . . . 1

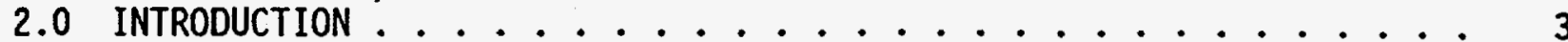

2.1 EVALUATION METHODOLOGY .................. 3

2.2 ACCELERATED SCHEDULE ................. 3

3.0 ANALYSES OF KEY ISSUES . . . . . . . . . . . . . . . . . . . 5

3.1 CREDIBLE AND DOCUMENTED DECISION LOGIC . . . . . . . . . 5

3.2 RETRIEVAL TECHNOLOGIES AND TANK WASTE CONTENT TYPES . . . . . . 5

3.3 MEASURE OF UNCERTAINTIES AND RELATIVE WORTH OF SYSTEM FACTORS - 5

3.4 EMPHASIS ON QUANTITATIVE ANALYSES, CONVERGENCE, AND DECISION

LOGIC . . . . . . . . . . . . . . ..... 6

4.0 RETRIEVAL SYSTEM CONCEPTS AND EVALUATION BASIS . . . . . . . . . . . 7

4.1 RETRIEVAL SYSTEM TECHNOLOGIES AND CONCEPTS CONSIDERED.$\cdots \cdots$

4.2 MATCHING RETRIEVAL SYSTEM ALTERNATIVES WITH SINGLE-SHELL TANK

WASTE CLASSES ..................... 9

5.0 EXAMPLES OF DECISION ANALYSIS TOOLS . . . . . . . . . . . 13

5.1 EXAMPLE: ANALYTICAL HIERARCHY PROCESS ........... 13

5.2 EXAMPLE: MULTIATTRIBUTE UTILITY ANALYSIS . . . . . . . . . 15

6.0 DECISION ANALYSIS AS AN EVALUATION TOOL IN

TECHNOLOGY SELECTION . . . . . . . . . . ....... 17

6.1 DECISION HIERARCHY . . . . . . . . ......... 17

6.2 STRATEGY TABLE . . . . . . . . . . . . . . . . . . . 19

6.3 DECISION TREE AS SYSTEM MODEL . . . . . . . . . . . . . . 21

6.4 TANK WASTE CLASSES FOR DECISION TREE . . . . . . . . . . . . . 21

6.5 DECISION TREE EXAMPLES FOR WASTE RETRIEVAL SYSTEM . . . . . . 23

6.6 QUALITATIVE INSIGHTS FROM DECISION TREE . . . . . . . . . . 29

6.7 SIMPLIFIED QUANTITATIVE ANALYSIS .................. 30

6.8 ELEMENTS OF COMPREHENSIVE MULTIATTRIBUTE UTILITY ANALYSIS . . . 35

7.0 KEY INSIGHTS, CONCLUSIONS, AND RECOMMENDATIONS . . . . . . . . 49

7.1 KEY INSIGHTS . . . . . . . . . . . . . . . . . 49

7.2 KEY CONCLUSIONS AND RECOMMENDATIONS ............ 49

8.0 REFERENCES . . . . . . . . . . . . . . . . . . . . . 51

APPENDIX A RETRIEVAL CONCEPT ACCEPTABILITY CRITERIA . . . . . . . . . . 53 


\section{DISCLAIMER}

This report was prepared as an account of work sponsored by an agency of the United States Government. Neither the United States Government nor any agency thereof, nor any of their employees, make any warranty, express or implied, or assumes any legal liability or responsibility for the accuracy, completeness, or usefulness of any information, apparatus, product, or process disclosed, or represents that its use would not infringe privately owned rights. Reference herein to any specific commercial product, process, or service by trade name, trademark, manufacturer, or otherwise does not necessarily constitute or imply its endorsement, recommendation, or favoring by the United States Government or any agency thereof. The views and opinions of authors expressed herein do not necessarily state or reflect those of the United States Government or any agency thereof. 


\section{DISCLAIMER}

Portions of this document may be illegible in electronic image products. Images are produced from the best available original document. 


\section{LIST OF FIGURES}

Figure

Page

4-1 Tank Farm Facilities--Quick Reference ........... 11

6-1 Single-Shell Tank Waste Retrieval Decision Analysis--Decision

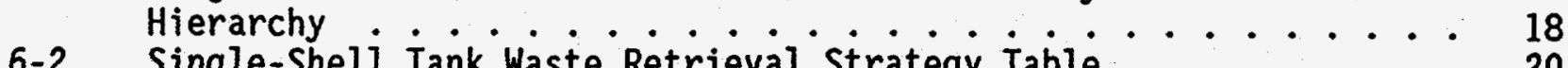

6-3 Decision Tree

6-4 Decision Tree--Demonstration/Sludge Waste Tank .......... 25

6-5 Decision Tree--Past Practice Sluicing Branch . . . . . . . . 27

6-6 Decision Tree--Combination of Retrieval Technologies ....... 28

6-7 Path 1: Desirable Outcome-- "Yes" Outcome at Every Node .... . 31

6-8 Path 2: Potentially Severe Detrimental Outcomes ........ 32

6-9 Path 3: Acceptable Outcomes with Downside Potential . . . . . 33

6-10 Path 4: Unsuccessful, Yet Benign Outcomes ........... 34

6-11 Hierarchy of Objectives ................ 37

6-12 Influence Diagram ................... 39

6-13 Portion of Influence Diagram for Detrimental Impacts . . . . 44

6-14 Example Probability Distribution Illustrating Output Available

6-15 From a Comprehensive Multiattribute Utility Analysis ......446 Example Illustrating Sensitivity Output Available From a

Comprehensive Multiattribute Utility Analysis ......... 47 


\section{LIST OF TABLES}

Table

4-1 Retrieval System Concepts ............... 10

4-2 Example of Retrieval Technologies Listed by Tank Waste Class . . . 12

5-1 Applying Analytical Hierarchy Process (AHP) . . . . . . . . 14

6-1 Ranking of Technologies with Respect to Factors Influencing the Probability of Achieving Technical Success in the 


\section{DECISION AND SYSTEMS ANALYSIS FOR \\ UNDERGROUND STORAGE TANK WASTE RETRIEVAL SYSTEMS \\ AND TANK WASTE REMEDIATION SYSTEM}

\subsection{EXECUTIVE SUMMARY}

Hanford's underground storage tanks (USTs) pose one of the most challenging hazardous and radioactive waste problems for the Department of Energy (DOE). Numerous schemes have been proposed for removing the waste from the USTS, but the technology options for doing this are largely unproven. To help assess the options, an Independent Review Group (IRG) was established to conduct a broad review of retrieval systems and the tank waste remediation system. The IRG consisted of the authors of this report.

The IRG's Preliminary Report assessed retrieval systems for underground storage tank wastes at Hanford in 1992. Westinghouse Hanford Company (WHC) concurred with the report's recommendation that a tool should be developed for evaluating retrieval concepts. The report recommended that this tool include (1) important considerations identified previously by the IRG, (2) a means of documenting important decisions concerning retrieval systems, and (3) a focus on evaluations and assessments for the Tank Waste Remediation System (TWRS) and the Underground Storage Tank-Integrated Demonstration (UST-ID).

As a first step to this decision tool development effort, the IRG focused on systems and decision analysis. One objective of developing a decision tool was to provide input into the TWRS and UST-ID. The Technology Development and Program Plans for the TWRS were scheduled for completion during August 1992, and similar near-term functions were scheduled for UST-ID. To satisfy these accelerated schedules, the IRG developed its methodology and process on a limited basis. The IRG's recommended decision analysis tool is described here, and illustrations are given of how it can be applied to evaluating retrieval systems.

This report is organized as follows. After an introduction, the key issues to be addressed by the decision analysis tool are described (Section 3). Section 4 describes the various retrieval concepts and how they are related to SST waste classes. Then two examples of decision analysis tools are given (Section 5). Section 6 discusses the use of decision analysis in decision-making. Finally, the IRG's key insights, conclusions, and recommendations are presented in Section 7 .

The IRG's most important recommendations and insights are as follows:

1. We highly recommend conducting a detailed decision analys is of tank waste retrieval systems. Such an analys is would provide decisionmakers with focused, in-depth evaluations, and, hence, maximum insight. Decision analys is would also offer a documented and credible basis for defending decisions.

2. There are many retrieval options. Pursuing parallel paths rather than focusing on a single technology will facilitate successful remediation 
of tank wastes. The decision analysis technique will greatly aid in selecting among the options, because it is thorough, forces a scrutable decision process, and identifies the key decision points and the uncertainties that follow decisions.

3. For a selected retrieval option, many things must go right. Each point of uncertainty requires a high probability of success to ensure overal1 success. In this regard, the use of methods of quantifying probabilities and consequences will heighten the credibility of decisions.

4. Not all retrieval options have decision choices and decision outcomes that are equally desired. For example, small amounts of leakage from a tank during a demonstration would be less problematic than a tank structural failure or a large-scale airborne release.

5. The DOE has accepted and successfully used decision analysis to provide quantitative measures of uncertainties and to determine the relative worth of different system factors.

6. Sensitivity analysis and decision analysis can help in determining whether certain key conclusions are independent of controversial assumptions. The debate could then be focused away from disagreements that do not affect decisions.

7. As the implementing organization, WHC should assume responsibility for how decision analysis is to be developed and conducted, with an emphasis on providing technology and technical understanding of retrieval systems and oversight of decision analyses. 


\subsection{INTRODUCTION}

In its earlier Preliminary Report, the Independent Review Group (IRG) evaluated the tank waste retrieval system and interface impacts from other program elements of the Tank Waste Remediation System (TWRS). The key conclusions of this systems approach were:

- More than one retrieval system technology is needed to address tank wastes characterized as ranging from sludges to concrete-like salt cakes.

- Nonrobotic retrieval systems (e.g., sluicing technologies) should be examined thoroughly before being eliminated from consideration.

- Parallel development paths, albeit at different stages, of more than one retrieval system technology may well be necessary.

- A methodology and process should be developed to evaluate the various retrieval concepts.

\subsection{EVALUATION METHODOLOGY}

WHC concurred with the IRG's recommendation to develop a methodology and process for evaluating retrieval concepts. This tool should:

- Include considerations identified previously by the IRG.

- Include a means of documenting important decisions concerning retrieval systems.

- Focus on in-depth evaluations and assessments for the TWRS and Underground Storage Tank-Integrated Demonstration (UST-ID) programs.

As an initial step, the IRG developed a set of Retrieval Concept Acceptability criteria (see Appendix A in Section 9.0). These criteria were based on the IRG's overall understanding of the storage tank waste retrieval program. Lawrence Livermore National Laboratory (LLNL) and Sandia National Laboratories (SNL) provided staff assistance in the area of systems and decision analyses, and Applied Decision Analysis of Men7o Park, CA, made a significant contribution as a subcontractor to WHC.

\subsection{ACCELERATED SCHEDULE}

The next phase of the IRG effort was to identify and develop a basic decision analysis tool as input into (1) the TWRS Technology Development and Program Plans during August 1992, and (2) similar functions on a timely basis for the UST-ID. To satisfy these accelerated schedules, we developed the decision analysis tool on a limited basis. This report describes the tool and illustrates how it is used to evaluate retrieval systems, including how a key branch of a decision tree could be quantified. 


\subsection{ANALYSES OF KEY ISSUES}

Several issues must be considered in the use of decision analysis tools to provide input to decision-makers. This section addresses issues of particular importance to the selection of retrieval system concepts.

\subsection{CREDIBLE AND DOCUMENTED DECISION LOGIC}

Decision analysis tools used to study the complex problems of retrieval systems must have two characteristics. First, a given method must meet the test of credibility and be accepted as a tool that is thorough and defensible in its logic. Second, the method should provide a documented and traceable basis of how the analysis was integrated. In addition, it should document the detailed analytical logic by providing the information, data, and conclusions upon which decisions were made.

\subsection{RETRIEVAL TECHNOLOGIES AND TANK WASTE CONTENT TYPES}

It is important to determine how various retrieval technologies are suited to (1) the retrieval of particular types of waste (e.g., sludges or salt cake), and (2) operation in a given range of circumstances (i.e., location and size of penetrations and in-tank hardware) in single-sheil tanks (SSTs) and double-shell tanks (DSTs) of the same waste class. Furthermore, retrieval systems must satisfy constraints imposed by safety considerations, such as the generation of hydrogen, the presence of ferrocyanide and organic compounds, and high-heat conditions.

In addition, a primary environmental consideration is the capability of detecting, monitoring, and controlling significant levels of leakage during retrieval operations.

\subsection{MEASURE OF UNCERTAINTIES AND RELATIVE WORTH OF SYSTEM FACTORS.}

A key element that UST-ID and TWRS will require in selecting technologies is the capability of identifying, measuring, and accounting for uncertainties. Criteria for closure, for example, can have a significant impact on retrieval systems. While decisions on technology development need to be made now, closure criteria may not be known for some time. Consequently, decisions and the analytical systems applied to support them, should have a means of quantifying uncertainties and incorporating their values into the decision analysis methodology.

In addition, the methodology needs to address the relative importance of different TWRS system factors. For example, the near-term schedule impact of using interim storage for retrieved waste must be compared with the impact of using a new or upgraded TWRS intertransfer system to convey waste from a confinement structure over the tank. 


\subsection{EMPHASIS ON QUANTITATIVE ANALYSES, CONVERGENCE, AND DECISION LOGIC}

In its earlier review, the IRG noted that system analyses did not usually quantify and integrate all of the factors involved. Such quantification facilitates the documentation and defensibility of decisions.

An essential ingredient of the decision analysis approach is that it provides an analytical logic that integrates a comprehensive range of factors. This logic offers a converging set of outcomes as focused input to decisionmakers. System options can thus be assessed in depth to determine their potential impact and to "work the problem" before a major decision is made. 


\subsection{RETRIEVAL SYSTEM CONCEPTS AND EVALUATION BASIS}

This section describes the types of retrieval concepts the IRG considered in developing an evaluation methodology and process. This section also describes a basic technique developed by the IRG to match retrieval technologies to single-shell tank (SST) waste classes.

\subsection{RETRIEVAL SYSTEM TECHNOLOGIES AND CONCEPTS CONSIDERED}

Numerous concepts have been suggested over the years for removing wastes from the Hanford SSTs. Because of the radioactive and hazardous nature of these wastes, the retrieval systems will require remote operations and 1 ikely remote maintenance. Retrieval system alternatives can be classified according. to the method with which wastes are extracted, handled, and removed from the tanks and transferred to the waste conveyance system. The four alternative classes are:

- Hydraulic

- Mechanical

- Pneumatic

- Mining entry

On the basis of information in WHC-EP-0405, by Boomer et al. (1992), a hydraulic retrieval system can be described as using liquid slurry transfers to move waste out of the tank. The equipment can include high-pressure, high-volume water jets with associated pumping and supply systems as well as accumulation tanks and recirculation systems. The waste is dislodged by water jet impact, dissolved or broken down, and washed into the vicinity of a slurry pump, where it can be pumped to the surface. The hydraulic retrieval system will not remove large-sized solid wastes that cannot be conveyed via a slurry. Also, the physical characteristics of some sludges can make the application of hydraulic retrieval systems difficult.

Mechanical retrieval systems can use a conveyance, such as a bucket elevator, to move waste out of the tank. The system relies on a remotely operated maneuvering device or mechanical arm and end effectors to break up waste, move debris, pick up waste, and deposit all waste into the bucket elevator for removal from the tank. When the bucket is full, it is withdrawn from the tank for loadout to the tank waste conveyance system. In general, a mechanical retrieval system requires a higher degree of positioning location control than do hydraulic retrieval systems, and there may be potential safety problems for certain waste classes, such as ferrocyanides.

Pneumatic retrieval systems use air conveyance to move waste out of the tank. A maneuvering and control system is used that: is similar to the one described for mechanical retrieval. The air conveyance system can use positive displacement blowers to produce high-velocity air for entraining the material, and cyclone separators to remove material particles from the airstream. The system transports liquids as well as dry materials. 
"Mining entry" refers to conventional mining technology that is used to enter an underground SST through either the tank sidewall, bottom, or an enlarged penetration in the tank's dome for the purpose of removing the waste. Types of mining technology may include various components and methods such as continuous miners, load haul dumpsters, and cut/cover tunneling. The IRG uses the term mining entry to distinguish retrieval systems removing SST wastes through the tank walls from the other methods, i.e., hydraulic, mechanical, and pneumatic. The latter may use mining methods or components to break up and extract wastes inside the tank for conveyance to the surface through conventional tank dome penetrations.

Each of the four waste retrieval systems has variations that incorporate special features. For example, a mechanical arm might utilize sluicing-type end effectors rather than a mechanical one, or a mechanical system might be used to break up the waste and process it for slurry removal from the tank.

For purposes of this IRG evaluation, the following discussion identifies the variations considered. In general, the IRG limited its analysis to hydraulic and mechanical retrieval systems. However, the methodology and process presented could readily be applied to pneumatic and mining entry systems. Hydraulic retrieval systems can consist of past practice sluicing (PPS) methods, which involve a transfer pump and one nozzle on a mechanical mast. Water is introduced through a jet on the mast end onto the waste, which is collected in a pool near the tank center, from where it is pumped out as a slurry. The devices can be lowered through an SST riser and powered by tethered systems (i.e., umbilical cords and cables) or mounted on rigid masts. The IRG identifies the PPS and minor variations as $h_{1}$ in Sections 5 and 6 . Other hydraulic systems include confined sluicing, mixer pumps, and hydrautic mining components inside the tank. Because hydraulic retrieval systems require the use of water in the tanks, consideration must be given to the development of tank leak detection and monitoring systems for these technologies.

The confined sluicing concepts are based on using multiple high-pressure but low-flow nozzles in conjunction with a nearby vacuum suction system to collect the water for recovery and transport to the surface. Confined sluicing systems use existing SST penetrations and, in principle, they use less water than PPS systems. General1y, these systems require more-precise positioning control than PPS systems and may be deployed by tethered systems or mechanical masts. If confined sluicing end effectors were used with mechanical arms, then the overall system would require a higher precision in positioning than that used in a tethered system. The IRG denotes confined sluicing systems as $h_{3}$ in Sections 5 and 6 .

Another alternative that may be considered for use with any type of hydraulic retrieval system is the installation of subsurface barriers under and around individual tanks or an entire tink farm. Concepts for such barriers could include (1) freeze barriers, and (2) grout or other water-impervious installations in vertical and, importantly, horizontal orientations. The function of the barriers would be to provide external confinement of possible contamination around the SSTs if a significant leak should occur during the addition of large amounts of water. Barriers should be used in conjunction with a leak detection system and would be left in place at least until site closure activities are initiated. The IRG uses the term 
$h_{2}$ to denote a PPS retrieval system coupled with a leak detection/monitoring system and subsurface barriers in Sections 5 and 6 .

The mechanical arm retrieval system can consist of a robotic arm deployed through an SST riser. The assumed concept uses a fixed telescoping arm arrangement with an attached articulated arm. The fixed telescoping arm would be mounted on a vertical, rotating extension column that provides vertical movement for the arm; the telescoping feature provides horizontal coverage. The articulated arm would consist of a number of sections and be attached to the end of the telescoping boom. Attached to the primary arm, the gantry or the telescoping type, is an articulating arm. The end of the articulating arm has provisions for remotely attaching the waste retrieval end effectors, which condition, prepare, and move the waste in the tanks as necessary during retrieval operations. Mechanical retrieval end effectors would include impact devices and pulverizers to dislodge and break up the hard tank wastes. Scrapers may also be used to clean the walls and floors of the tanks. A clamshell bucket or grabber device will be used to move the loose waste into the batch conveyance system. The IRG uses the notation $m_{1}$ to denote such a mechanical arm and conveyance system in Sections 5 and 6 .

Table 4-1 summarizes the technologies and concepts used in retrieval system evaluations by the IRG. The terms $h_{1}, h_{2}, h_{3}$, and $m_{1}$ are introduced and defined for use in Sections 5 and 6 . The retrieval systems all require some technology development, albeit at different and varying levels, in order to be deployed. Sections 5 and 6 use the capital letter terms $H_{1}, H_{2}, H_{3}$, and $M_{1}$ to represent examples of the set of necessary technology development activities that need to be completed prior to deployment of a specific retrieval system type. For example, $\mathrm{H}_{1}$ includes technology development activities for items such as pump nozzles, leak detection and leak monitoring systems, and slurry handling components. $H_{2}$ includes $H_{1}$ activities and those required to develop and install subsurface barriers. $H_{3}$ includes many activities in $H_{1}$ as well as additional technology development activities associated with the likely requirement of more precise positioning control than $\mathrm{H}_{1}$ and sluicing liquid vacuum recovery components. $M_{1}$ includes development of high precision positioning technology, mechanical end effectors, and mechanical conveyance system components. More detailed lists of technology development requirements could be developed for each of the different retrieval systems, but for this IRG analysis, the descriptions were limited to the technology development areas discussed previously.

\subsection{MATCHING RETRIEVAL SYSTEM ALTERNATIVES WITH SINGLE-SHELL TANK WASTE CLASSES}

The 149 single-shell tanks (SSTs) and 28 double-shell tanks (DSTs) contain an inventory of wastes with a wide variety of physical, chemical, and radiological constituents. The monthly report series WHC-EP-0182-XX (Tank

Farm Surveillance and Waste Status Summary Report) gives a tank-by-tank waste description and inventory. These reports present summary data based on types of waste constituents and their classifications. Figure 4-1 is an example taken from this report. It condenses key categories, such as tank contents associated with important safety issues (high heat, $\mathrm{H}_{2} / \mathrm{fl}$ ammable gases, ferrocyanide, and organics) and interim stabilization status. 
TABLE 4-1. Retrieval System Concepts

\begin{tabular}{|c|c|c|}
\hline $\begin{array}{l}\text { IRG Analysis } \\
\text { Code }\end{array}$ & $\begin{array}{l}\text { Retrieval System } \\
\text { Classification } \\
\end{array}$ & Description \\
\hline$h_{1}$ & Hydrautic & $\begin{array}{l}\text { PPS, with leak } \\
\text { detection and } \\
\text { monitoring system }\end{array}$ \\
\hline$h_{2}$ & Hydraulic & $\begin{array}{l}\text { PPS, with leak } \\
\text { detection/monitors and } \\
\text { subsurface barriers }\end{array}$ \\
\hline$h_{3}$ & Hydraulic & $\begin{array}{l}\text { Confined sluicing with } \\
\text { leak } \\
\text { detection/monitors }\end{array}$ \\
\hline$m_{1}$ & Mechanical & $\begin{array}{l}\text { Mechanical arm, with } \\
\text { grabber type end } \\
\text { effectors and } \\
\text { mechanical conveyance } \\
\text { to surface }\end{array}$ \\
\hline
\end{tabular}

The planning of SST, or DST for that matter, retrieval systems would benefit from the use of a similar representation of tank waste classes based on predominant physical descriptions, such as sludge, salt cake, or mixtures, and waste type. For all 149 SSTs, waste classes could be matched with retrieval technologies that are either (1) available for modification and application, (2) being developed, or (3) contemplated as a realistic candidate for development. Such matching could be a first framework for assessments of retrieval systems. If such general waste classes were defined and incorporated into an assessment of retrieval concepts, benefits could be identified and possibly quantified.

For the purposes of this evaluation in Sections 5 and 6 , the following four SST classes are identified:

- Sludges

- Salt cakes

- Mixtures

- Concrete-like 


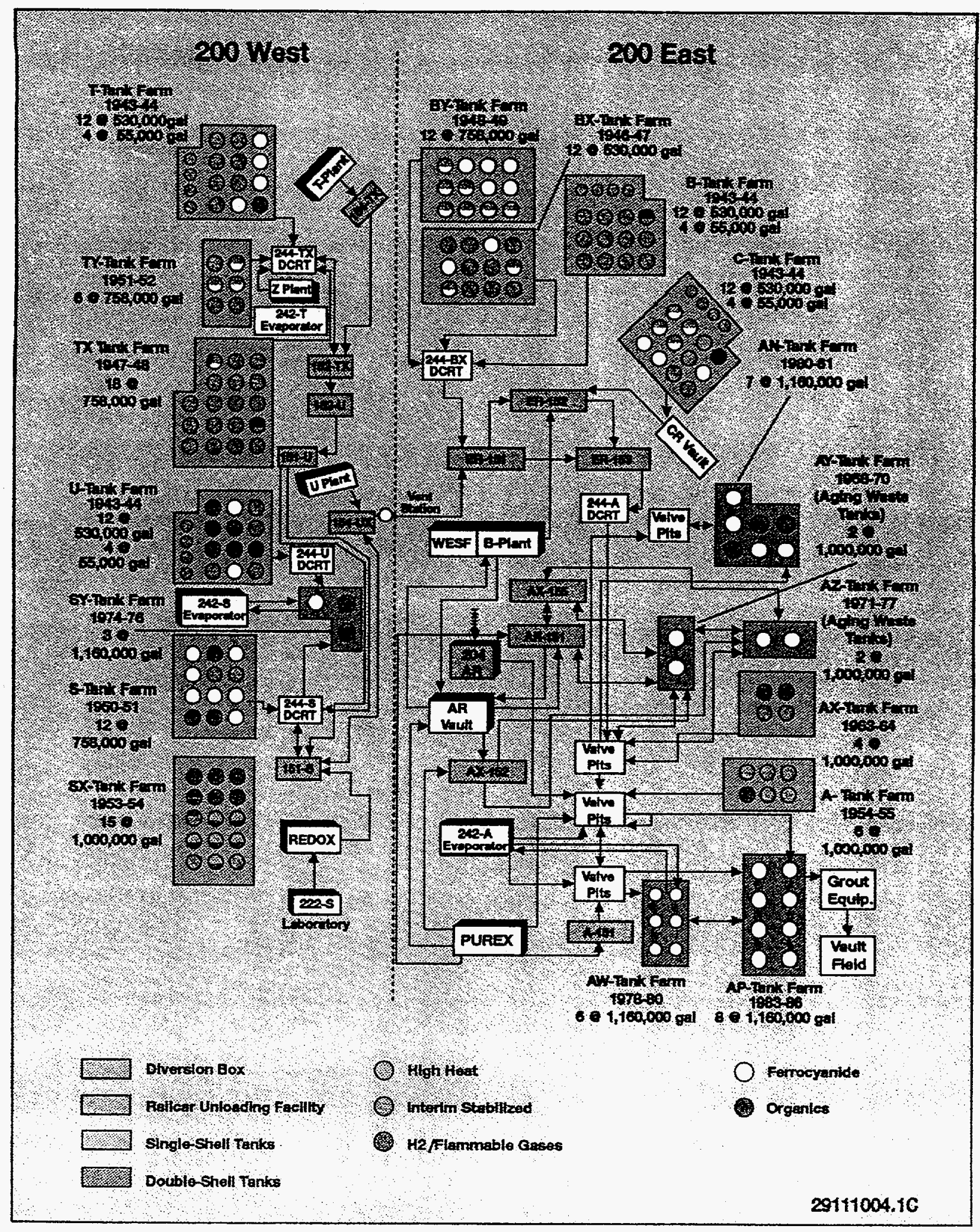

Figure 4-1. Tank Farm Facilities--Quick Reference 
An initial estimate of the types of retrieval systems needed can be made by mapping them to the four waste classes in a format similar to that in Figure 4-1. This estimate would take into account the level and status of technology development of each retrieval system. Table 4-2 illustrates such a comparison, with the number of SSTs in each waste class to be determined (TBD) during this type of assessment.

While the example presented is oversimplified, this approach--in which the underground storage tank (SSTs and DSTs) characterization data base and groupings are compared with various retrieval concepts--could provide valuable insights. In addition, applying this approach in an interactive manner with increasing information and data on tank waste characterization and internals would provide an instructive tool for decision and system analyses. This approach would also provide a documentable means of planning retrieval system development.

TABLE 4-2. Example of Retrieval Technologies Listed by Tank Waste Class

\begin{tabular}{llll} 
Waste Class & \multicolumn{2}{c}{$\begin{array}{c}\text { Number of } \\
\text { SSTs in Grouping }\end{array}$} & $\frac{\text { Retrieval Technologies }}{\text { Alternative }}$ \\
Sludges & TBD & PPS $\left(h_{1}\right)$ & Arm $\left(m_{1}\right)$ \\
Salt Cake & TBD & PPS $\left(h_{1}\right)$ & Arm $\left(m_{1}\right)$ \\
Mixture & TBD & PPS $\left(h_{1}\right)$, Arm $\left(m_{1}\right)$ & None \\
Concrete-1ike & TBD & Arm $\left(m_{1}\right)$ & Mining \\
\hline
\end{tabular}

Note: PPS, past practice sluicing; Arm, mechanical arm; Mining, mining entry as described in Section 4.1. This example has not been based on an actual decision analysis or technical evaluation of alternatives. It is intended to illustrate the manner in which waste classes and candidate retrieval technologies can be grouped and compared. 


\subsection{EXAMPLES OF DECISION ANALYSIS TOOLS}

Several decision analysis tools are available. In general, tools that are quick and easy are often not precise, and those that offer better precision and have a firm mathematical basis require a significant effort to implement. The selection of a tool for a particular decision and system analysis problem must be guided by several issues, including the significance of the decision in terms of cost, safety, the time available for making the decision, and the degree to which the decision must withstand scrutiny.

\subsection{EXAMPLE: ANALYTICAL HIERARCHY PROCESS}

One tool available to decision-makers is called the Analytical Hierarchy Process (AHP). In this process, the opinions and knowledge of experts or decision-makers are analyzed through a process of pair-wise comparisons of issues viewed as important to making a particular decision. In general, AHP serves as a more formal decision process than a group discussion, consensus, and voting process, but it falls short of the formalism of the decision analysis technique described in Section 6.

For purposes of this report, the IRG explored some of the capabilities of AHP by applying an AHP software package entitled Expert Choice. This package, developed and marketed by Dr. Thomas L. Saaty of the University of Pittsburgh, has been used widely by several government and private organizations, including IBM and DOE's Office of Planning and Assessment for Conservation and Renewable Energy.

For this exercise, the IRG applied AHP on a limited basis and considered only four retrieval options: past practice sluicing (PPS) with detection and monitoring systems, PPS with detection/monitors and subsurface barriers to contain leakage, confined sluicing, and mechanical retrieval using roboticsintensive technology. For each of these retrieval options, the IRG compared the issues and concerns listed in Table 5-1 using a formal pair-wise comparison technique and numerical rating scheme that captured the relative importance, in the view of each IRG member, of each factor.

Because this assessment was performed independently by each IRG member without attempting to reach consensus at the outset, the results of the AHP evaluation to a large extent reflected the integrated knowledge obtained by each IRG member since January 1992, based on the Hanford documents reviewed, the numerous IRG meetings with WHC personne], and other documents reviewed to date.

This exercise by the IRG revealed several of the shortcomings of the AHP process, particularly the need for consistent interpretation of the factors used in the pair-wise comparisons and a consistent calibration of the relative values of the factors. Despite the shortcomings, each member of the IRG rated the PPS, with leak detection/monitoring, retrieval option over any of the other options by at least a factor of 2 overal1. In specific categories, there was unanimous agreement amongst the IRG members regarding the favorable ranking of PPS. In particular, the IRG considered the PPS with detection option as very favorable in terms of its support of near-term retrieval (i.e., schedules, cost, operability, and safety categories). In general, the IRG 
TABLE 5-1. Applying Analytical Hierarchy Process (AHP)

Develop/Implement Robust Retrieval Technology

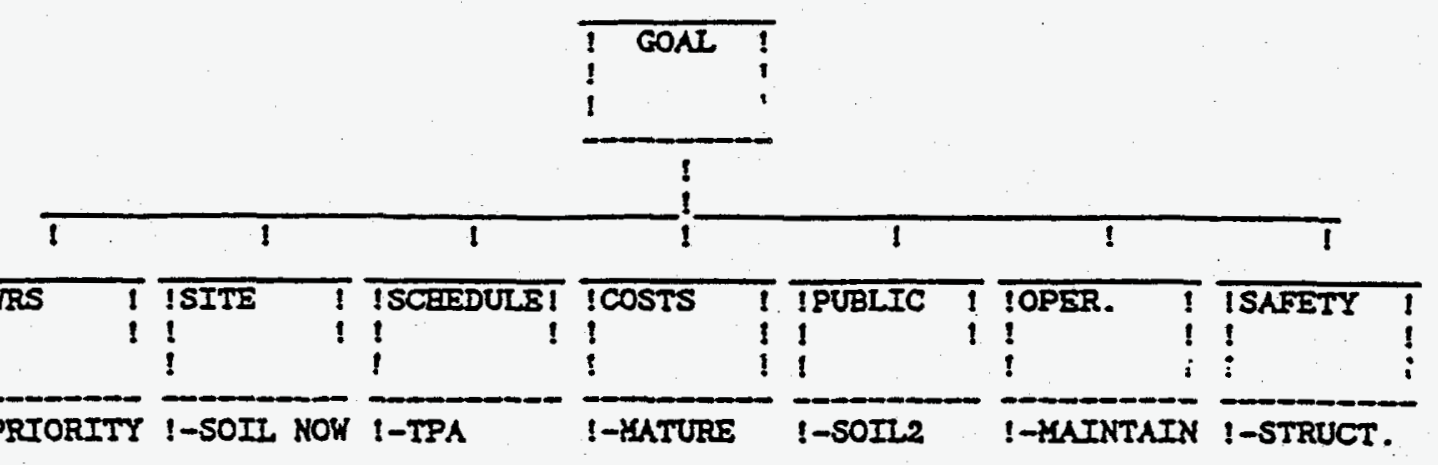

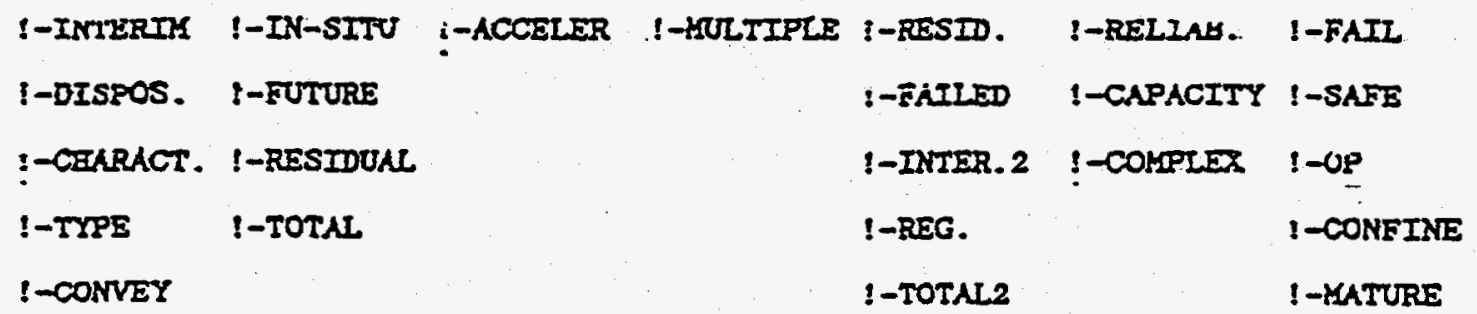

1 -INERA

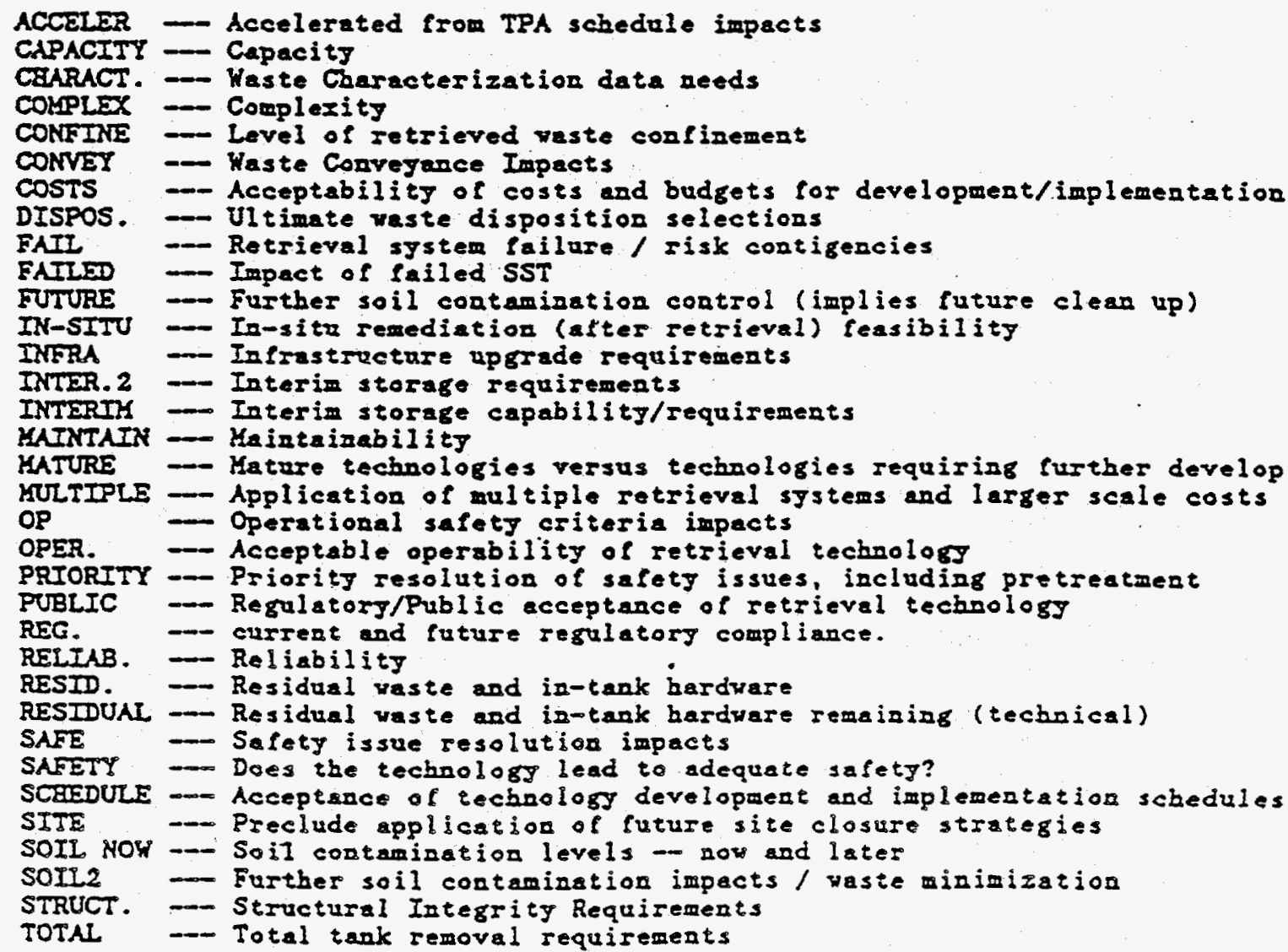


viewed PPS with detection as favorable to other retrieval options with regard to public acceptance. However, this rating was contingent upon the ability to demonstrate that any leakage that would occur during sluicing retrieval could be shown to be small.

The IRG found AHP to be a powerful questioning device that is flexible and easy to use. Necessary inputs may be readily obtained, and the technique permits decision options to be evaluated and ranked quantitatively, even in situations in which the relevant considerations have not been previously quantified. The approach has an extensive track record; it has been applied in numerous fields including business, energy, health, transportation, sociology, economics, and politics (Zahedi, 1986).

AHP, however, has several significant weaknesses that limit its usefulness. First, AHP is unable to address explicitly the uncertainties inherent in decisions. For example, uncertainties involving the capabilities of alternative technologies or the possibility of low-probability, high-consequence events cannot be incorporated into AHP in any rigorous fashion. The process of making the necessary pair-wise comparisons can also be tedious for participants: if the hierarchy of considerations developed for the AHP is complex, the number of comparisons that must be made is very large. The concept of "importance" used in comparisons is ambiguous and often leads to inconsistencies in inputs. Furthermore, results can be easily manipulated by participants in favor of a prespecified alternative (Harker, 1987; Belton and Gear, 1983; Winkler, 1990).

Perhaps the most serious criticism of AHP is the charge that the rankings produced by this technique are arbitrary (Dyer, 1990; Schoner and Wedley, 1989). A symptom of this flaw is the phenomenon associated with AHP known as rank reversal. Rank reversal occurs when the addition of an alternative that is identical to another alternative causes the relative ranking of two or more of the other alternatives to change. For instance, AHP might rank three alternatives $A, B$, and $C$ such that $A$ is preferred to $B$ and $B$ is preferred to $C$. However, when alternative $D$, which is similar to $C$, is added, the ranking of $A$ and $B$ may be reversed. Critics charge that the problem of rank reversal disqualifies AHP as a defensible decision logic.

\subsection{EXAMPLE: MULTIATTRIBUTE UTILITY ANALYSIS}

Multiattribute Utility Analys is (MUA) is a more rigorous approach for evaluating decision alternatives that avoids the limitations of AHP (Hobbs, 1979; Keeney and Raiffa, 1976). MUA results in logically defensible rankings of alternatives, does not produce rank reversals, and explicitly handles uncertainties. Like AHP, there have been many applications of MUA in diverse areas. However, because MUA is based on utility theory, it has stronger theoretical underpinnings. As a result, MUA is well suited tr iccisions that involve uncertainty, complexity, and a need for a solid, defensible justification (Raiffa, 1968; Howard, 1968).

The main limitations of MUA are that it is more difficult to apply than AHP, because it requires "soft" issues to be quantified, and the multiple attributes of outcomes must be combined into a single measure of value. Nevertheless, as will be demonstrated in Section 6, an in-depth, comprehensive MUA is not required to produce important insights into a decision. Additional 
advantages of MUA are the abilities to perform sensitivity analysis and to calculate the value of obtaining information to resolve uncertainties.

Section 6 illustrates the potential for applying MUA to aid decisionmakers in the field of tank waste retrieval systems. A simple pilot application of MUA is presented and results in several useful problem insights. 


\subsection{DECISION ANALYSIS AS AN EVALUATION TOOL IN TECHNOLOGY SELECTION}

Of the available decision analysis approaches, the relatively rigorous approach known as multiattribute utility analysis (MUA) appears well suited to facilitate decisions related to tank waste retrieval systems and the UST-ID. The selection of retrieval technologies, which involve large economic costs and impact the potential risks to public health and safety and whose operations will be conducted over relatively long time frames, needs to withstand the scrutiny of interested parties. The large investment and importance of identifying and developing workable retrieval system technologies to satisfy Tri-Party Agreement (TPA) Milestones argues for the use of an accurate evaluation methodology. The anticipated scrutiny recommends decision processes that make the reasoning behind choices explicit and logically defensible.

Although available time for the IRG's phase 2 did not permit a full MUA application as part of this study, the three basic elements of an evaluation methodology based on MUA have been developed. These are (1) a decision hierarchy of tank waste retrieval decisions, (2) a strategy table, and (3) a decision tree. These elements represent the foundation for conducting a full-scale application. In addition, illustrative examples using these elements permitted a simple analyses to be made by the IRG from which useful insights have been drawn.

\subsection{DECISION HIERARCHY}

Figure 6-1 is a decision hierarchy, listing many of the decisions relevant to the selection of a retrieval technology for the single-shelled tanks. The shaded portion of the hierarchy lists the decisions which would represent the primary focus of a full MUA evaluation. The decision types represented in the shaded area were also the focus of the analys is example conducted by the IRG. The upper portion of the hierarchy lists decisions which were assumed to be "given." That is, the analysis assumed that these decisions have already been made, and they are not being re-evaluated at this time. For example, the analysis assumed that the decision to remove waste from the tanks has been made, and that decision is not being revisited. Similarly, regulatory requirements are taken as given and the analysis did not re-evaluate which requirements are appropriate and which are not. (Although such decisions may need to be re-evaluated, this decision hierarchy indicates and documents that such re-evaluation is not part of this analysis).

The lower portion of the hierarchy also lists decisions that were not evaluated in this analysis. They are lower-level decisions related to waste-retrieval options that will need to be evaluated sometime in the future. However, for this analysis, a base line choice was assumed for each decision and the analysis proceeded following the assumptions about how the lower-level decisions would be made. For example, the analysis assumed that the retrieval technology design will be completed and workable, that operating procedures will be defined, that the appropriate infrastructure will be in place, and so on. In the future, such decisions may have to be analyzed explicitly; for now, given the relatively greater importance of decisions in the shaded 


\section{SST Waste Retrieval Decision Analysis} Decision Hierarchy

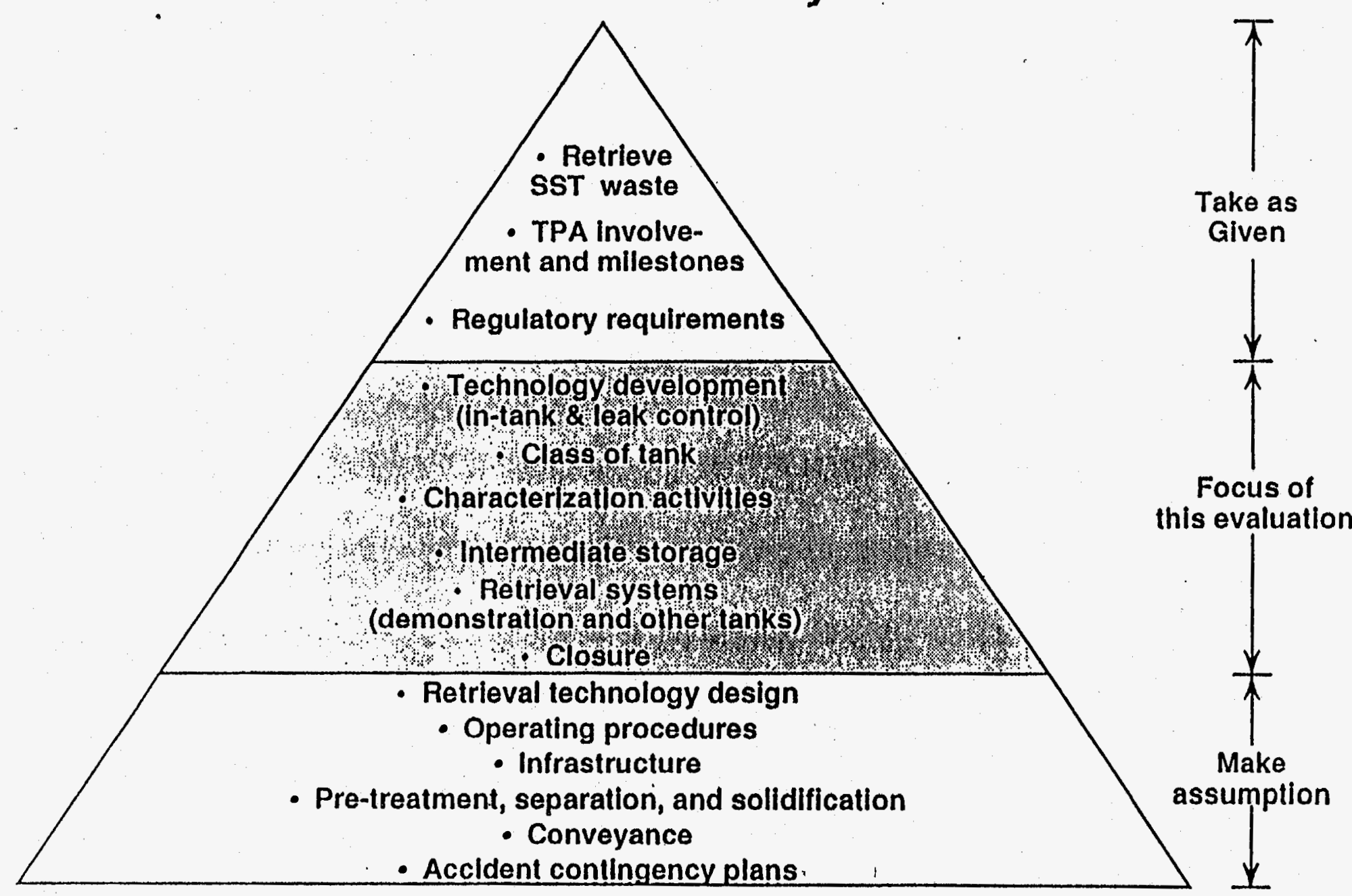

$7 / 15 / 92$

FIGURE 6-1. Single-She11 Tank Waste Retrieval Decision Analysis--Decision Hierarchy 
portion of the hierarchy, these "make assumption" decisions were not evaluated.

The shaded portion of the hierarchy lists those decisions which would be analyzed explicitly in a full decision analysis and which were partially addressed in the simple analysis that was conducted by the IRG. These include decisions related to:

- Tank waste class for the first retrieval system demonstration

- Technologies to develop for waste retrieval and leak control

- Further characterization activities of the tank and its contents

- Retrieval system to use for the demonstration tank and for other tanks

- Intermediate storage of retrieval wastes

- Closure requirements for the tanks

Specifically, the decision analysis would evaluate the major options for each of these decisions and identify the best option for each decision.

\subsection{STRATEGY TABLE}

Figure 6-2 is a "strategy table" identifying the primary options for each of the major decisions from the shaded portion of the decision hierarchy. For example, the first column of the strategy tabie lists options for retrieval system technology(ies) development: hydraulic, pneumatic, mechanical, mining entry, and combinations of these techniques.

Note that there is a column in the strategy table for each decision in the shaded portion of the decision hierarchy, but that decisions in other parts of the hierarchy are not represented here. Also note that this table does not represent all factors relevant to the decisions being made, it simply lists the critical decisions and some major options for those decisions. other factors, such as uncertainties about requirements, effectiveness of the technologies, and so on, are accounted for in a separate part of the decision analysis.

The strategy table lists several options for each decision, which can be combined in many ways. For example, one strategy is: develop hydraulic retrieval technologies with leak control and detection techniques, choose a sludge tank for the demonstration, characterize the physical properties of the tank, use new tanks for intermediate storage, and have no special activities at closure. A second strategy would be the same set of options up to closure, but with tank removal as a closure requirement.

Obviousiy there are many different combinations of options represented by the table (in fact, there are 3200 combinations in this simple example table). Theoretically, all options could be evaluated in the decision analysis, but the use of the strategy table helps reduce the amount of analys is which must be done. Even in the absence of quantitative anaiysis, it is apparent that many strategies will be inferior. For example, trying to use a pneumatic retrieval strategy for the demonstration when only the hydraulic techniques have been developed will clearly be a less valuable strategy.

In a full-scale decision analysis, many combinations of options would be quantified and evaluated. However, the process of creating reasonable 
SST Waste Retrieval

Strategy Table

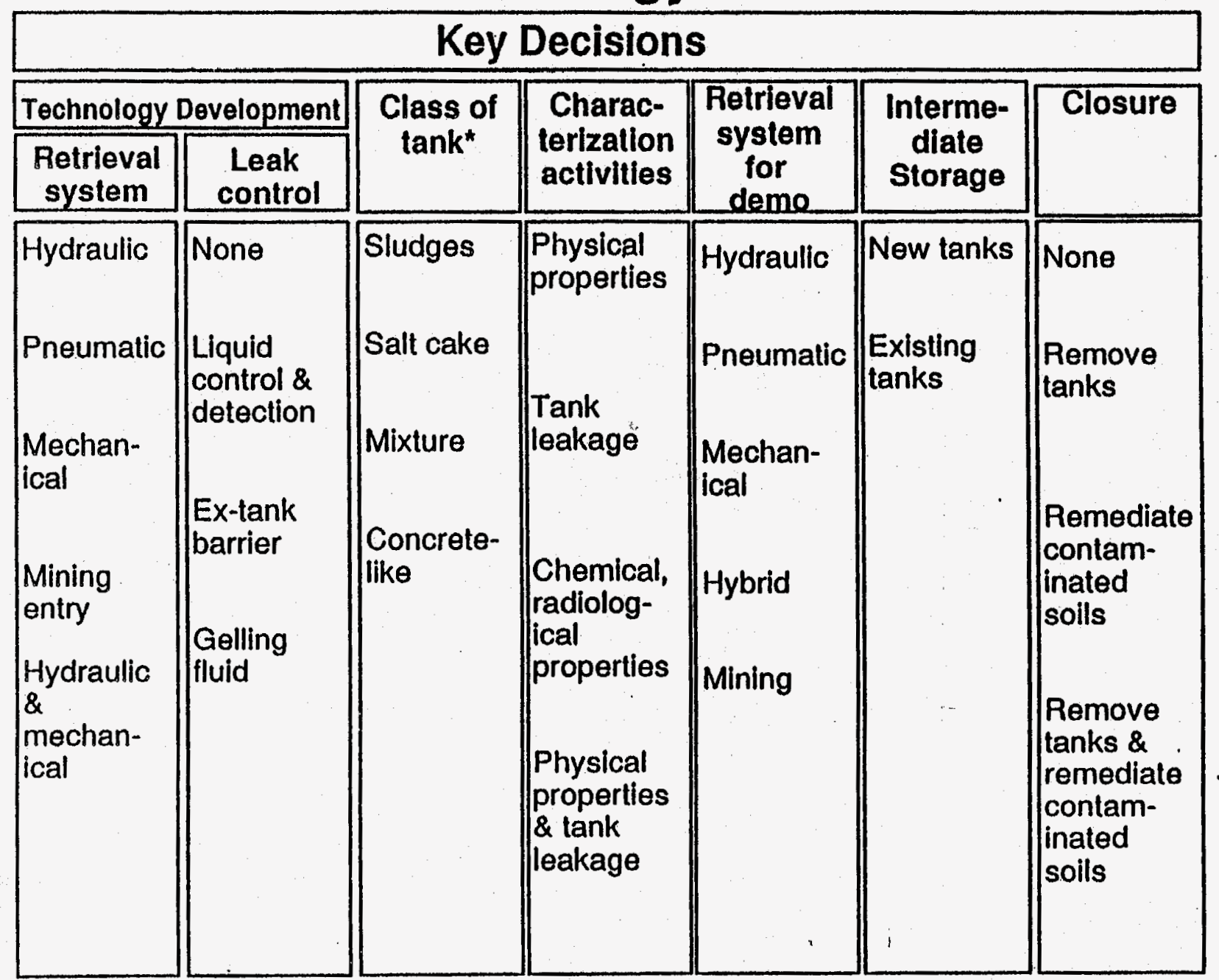

"Class may include a description of safety issues (ferrocyanide, flamable gas, organic salts, high heat)

FIGURE 6-2. Single-Shell Tank Waste Retrieval Strategy Table 
strategies from the options in the strategy table is an important simplifying step early in the process. It involves doing some intuitive thinking early on to eliminate clearly inferior strategies so that time and effort is not wasted quantifying and analyzing these strategies.

\subsection{DECISION TREE AS SYSTEM MODEL}

Applications of MUA often require the development of a decision tree. A decision tree is a model that enables the analysis to account explicitly for key uncertainties and the dynamic nature of the decision process (Bunn, 1984). Figure 6-3 shows an example decision tree potentially useful for an MUA of tank waste retrieval systems. Decisions and uncertain events are represented in the tree by nodes (circles for uncertainties, squares for decisions). . The branches emanating from a node indicate a7ternatives for decisions or outcomes for uncertain events. Time moves from left to right, so that the order of the nodes in the tree indicates the order in which decisions must be made and outcomes are revealed. The decision tree shown in Figure 6-3 is a "generic" tree in the sense that it does not show how decision choices influence subsequent uncertainties. More detailed trees, to be presented later, indicate how uncertainties (circles) are connected to branches from decisions (squares).

The three major decisions in the decision tree (represented by boxes in the diagram) correspond to the decisions listed in the strategy table. Specifically, the first decision in the decision tree (select retrieval technologies for development) includes the first two decisions in the table (retrieval system technology development and leak control technology development). That is, when an option for the first decision in the tree is defined, it includes both the technologies being developed for retrieval and the technologies being developed for leak control.

Similarly, the second decision in the tree includes both the choice of retrieval system for the demonstration and the intermediate storage decision from the table. The third decision in the tree (select type of tank for demo) includes both the "class of tank" and the "characterization activities" decisions from the strategy table. The fourth decision in the tree includes a decision about the retrieval systems for other tanks in the waste class.

\subsection{TANK WASTE CLASSES FOR DECISION TREE}

As discussed in Section 4.2, the underground tanks contain a variety of waste types. By grouping the tanks into a limited number of waste classes and associating retrieval system technologies that are either (1) currently available, or (2) needing further development, or (3) an alternative that could be developed, a useful planning approach is provided that can be employed to aid decision-makers. This approach is significant because the various waste classes of tanks based on current characterization information and so defined, would have a substantial positive impact by focusing the choice of retrieval technologies selected for future development and deployment. Consequently, such early definition and planning will aid in selecting the most appropriate retrieval system or combination of retrieval systems that need to be applied to each of the underground tanks. Also, this approach facilitates the definition of waste retrieval systems and their 


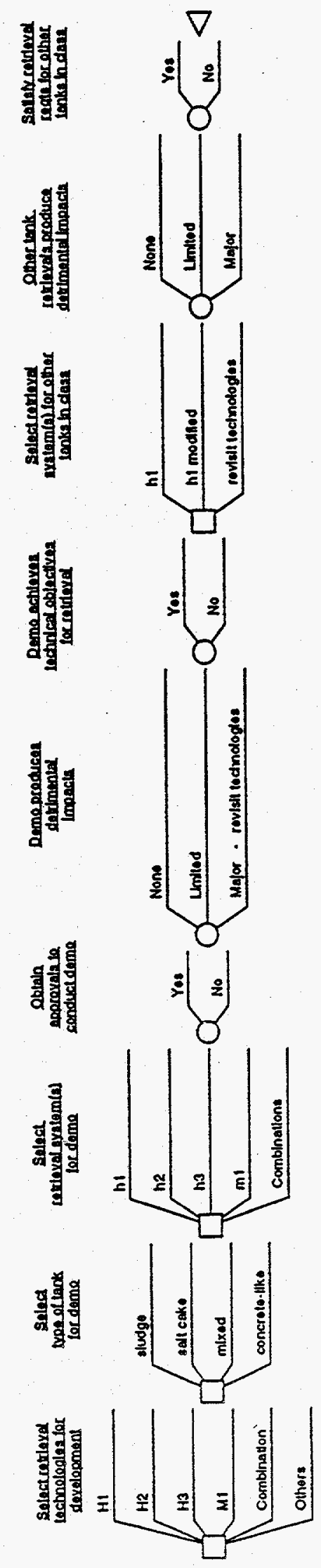

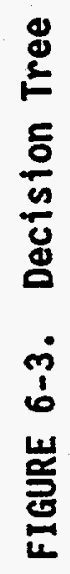


associated technologies and provides a focus upon which to base both their development and deployment.

Table 4-2 shows an analogous approach that could be used to communicate, summarize, and apply the method described in Section 4.2. This mapping of (1) tank waste classes with (2) retrieval system technologies assists decision-making related to current development planning and deployment in the future. To further illustrate how defining wastes classes and matching with the most likely types of retrieval system can be used in decision analyses, the same simplified example of four tank classes in Section 4.2 are used:

- STudgès

- Salt cakes

- Mixtures

- Concrete-1ike

It is recognized that there may eventually need to be more than four tank waste classes, or at a minimum, an additional class to account for in-tank hardware and larger-sized, other solid waste materials. This refinement of tank waste classes could be done as retrieval system technologies are developed and demonstrated, as well as further characterization of waste tank constituents completed. However, significant insights would be gained for the initial planning processes and technology selection using a more 1 imited classification of tank waste, as shown in the preceding section and in Section 4.2. In using these four classes in the decision tree discussed in Section 6.3, their importance is stressed by making them the first series of "branches" after the selection of the "path" for the "retrieval technology selected for development."

\subsection{DECISION TREE EXAMPLES FOR WASTE RETRIEVAL SYSTEM}

A decision tree can be used to aid decision-makers in either a qualitative or quantitative mode. In the qualitative mode, the decision tree provides a map of the decision process. Just as a road map helps a driver plan a trip, a decision tree can help decision-makers plan a decision. A road map shows aiternative routes for reaching a destination and indicates how initial choices affect the options available for subsequent choices. Some choices may be familiar, yet a closer study may reveal routes that might otherwise be overlooked. In the same way, the decision tree lays out a spectrum of possibilities, some of which might represent new considerations or possibilities for action, while others may limit future flexibility. Another benefit common to both road maps and decision trees relates to information gathering. By indicating the characteristics of the routes that might be selected, the road map invites the driver to collect potentially useful information. For example, an upcoming choice between a freeway and backroad might be aided by local weather and traffic reports. Similarly, the decision tree alerts decision-makers to upcoming decisions and suggests the information necessary to resolve the uncertainties that influence their choices.

In the quantitative mode, a decision tree may be solved to identify a "best" decision strategy. This requires assigning probabilities to each uncertainty node and consequences to each path through the tree as a function of the options that are selected. The desirability of the various consequences can be expressed by developing a multiattribute utility function. 
The multiattribute utility function is an equation that converts the consequences of the decision (e.g., effects on human health and the environment, cost, and schedule) to a measure of desirability called utility. The option that is best, according to MUA, is the choice that leads to the highest expected utility, where expected utility is the sum of the utility of the consequences associated with each path through the tree weighted by the probability of that path. The option with the highest expected utility can be shown to be the option most preferred by a decision-maker, provided that the probabilities reflect the decision-maker's uncertainties, the utilities assigned to consequences reflect the decision-maker's preferences for those consequences, and decision-makers accept several basic axioms of rationality.

Use of a decision tree to evaluate options quantitatively is described in more detail in Section 6.7 .

As described above, a decision tree can be developed to guide the selection of retrieval system technology development and retrieval system demonstration. In fact, a decision tree for retrieval system technologies can be extended to help guide future decisions for applying retrieval technologies to a given class of tanks as part of the complete waste retrieval program.

For purposes of this report, three representative decision tree branches were developed in detail, reflecting key decision points and uncertainties associated with the outcomes of decisions. Figure 6-4 shows one decision tree branch in which a combination of retrieval technologies is assumed to be developed, followed by the decision to select a particular tank as an initial demonstration of technology. In this case, a sludge-containing tank is chosen. The next key decision is to select the type of retrieval system used for demonstration purposes. After this decision, a number of uncertainties follow which could lead to success, limited success, or failure. The first uncertainty involves the success to which necessary approvals to conduct the demonstration are obtained. Next, uncertainties are shown for detrimental impacts that could occur during a demonstration (e.g., excessive leaks or accidents) and for the ability of the selected technology and demonstration to achieve the technical objectives of retrieval $(\mathrm{e} . \mathrm{g}$. , completeness of waste removal, dilution of waste streams, reliability, maintainability, and so forth). Figure 6-4 shows that after the demonstration has been completed, another decision will need to be made involving the selection and use of the demonstrated retrieval system on other tanks in a class--in this case sludge-containing tanks. Following this decision, there are two more uncertainties that result. One involves the extent to which the selected retrieval system causes detrimental impacts for other tanks in the class during retrieval, and the other involves the degree to which the selected

\footnotetext{
"This is known as the "expected utility theorem." The expected utility theorem provides the theoretic justification for MUA. That the axioms are readily accepted by most people may be illustrated by an example of one of the axioms, transitivity of preferences--if a decision-maker likes option $A$ better than option $B$ and option $B$ better than option $C$, then the decisionmaker must like option A better than option $C$. A description of the six axioms is presented by Stokey and Zeckhauser (1978). A complete mathematical treatment of the theory is provided by Luce and Raiffa (1957).
} 


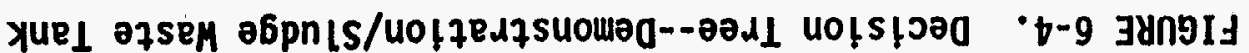

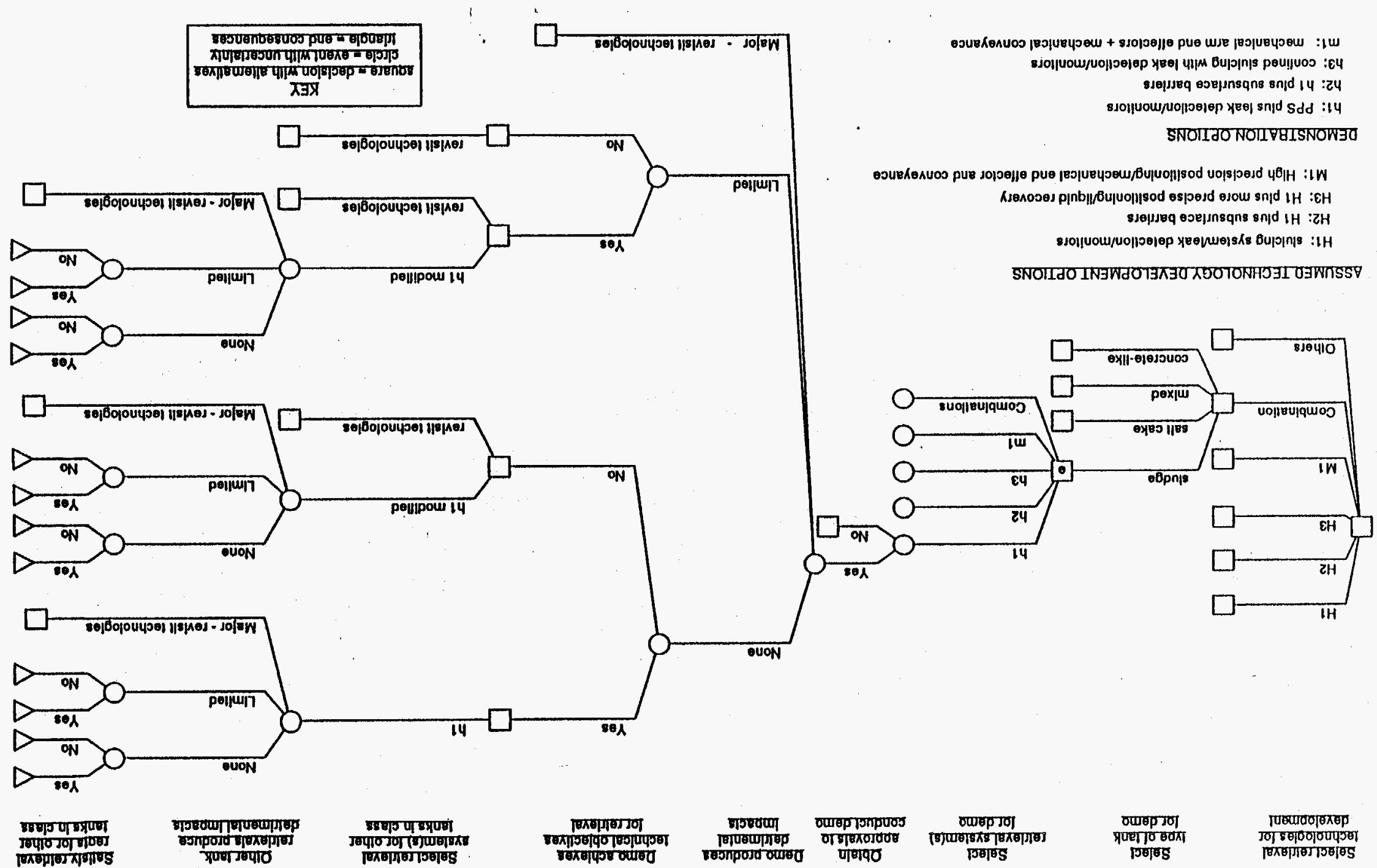


technology will satisfy retrieval requirements for other tanks. These two uncertainty nodes are anticipated because, although tanks may be grouped into classes, each single-shell tank has a unique operational history and waste contents.

Figure 6-5 shows a different branch of the decision tree. In this branch, a decision is made to develop only one retrieval technology. The retrieval technology selected is practice sluicing with detection (i.e., $H_{1}$ ). For this case, the selected retrieval system for the demonstration would have to be $h_{1}$, because there would be no option to consider the use of other hydraulic, mechanical, or combinations of systems for retrieval. If it is again assumed that $h_{1}$ will be demonstrated on a sludge-containing tank, the uncertainties associated with obtaining approvals for the demonstration, conducting the demonstration with no detrimental impacts, and achieving the technical objectives for retrieval with the selected technology are the same as before. At first, Figures 6-4 and 6-5 appear very similar. However, it should be clear that in the case of Figure 6-5, if problems should arise during the demonstration, due to either detrimental impacts or ineffectiveness of the technology to achieve retrieval objectives, then the branches entitled "revisit technologies" are much less attractive in Figure 6-5 than Figure 6-4. "revisit technologies" implies reconsidering the decision to select the retrieval system for demonstration (third decision in Figure 6-4, shown as " $\mathrm{e}$ ), perhaps choosing a different hydraulic, mechanical, or combination or retrieval options. In the first decision tree, the choice to reconsider the retrieval system selection decision, or at " $e$ ", results in time and budget impacts related to reperforming a demonstration. However, because in this. first branch a combination of retrieval technologies was developed before making the decision to apply a particular technology to a particular type of tank, other technologies presumably could be applied relatively quickly in another demonstration. This is not the case for the second decision analysis diagram (Figure 6-5), because the decision was made early in the process to develop only one type of retrieval technology. In this second case, the requirement to "revisit technologies" would require returning to technology development activities, as opposed to applying developed technologies to a new demonstration--a result which would cause larger schedule delays and potentially higher costs.

Figure 6-6 shows yet a third option. In this figure, it is assumed that a combination of retrieval technologies is developed and the selection of a sludge tank for first retrieval demonstration is made. However, instead of choosing a past practice sluicing with detection technique. (Figures 6-4 and $6-5)$, a mechanical arm (with end effectors or $m_{1}$ ) retrieval technology is chosen for demonstration. From this point on, the decision analys is tree follows a path which, at first, appears to be exactly as that shown in Figures 6-4 or 6-5. The difference in this case, however, is that the uncertainties associated with obtaining demonstration approvals, experiencing detrimental impacts during the demonstration, successfully achieving technical objectives during the demonstration, experiencing detrimental impacts during retrieval of other tanks, and satisfying retrieval objectives for other tanks 


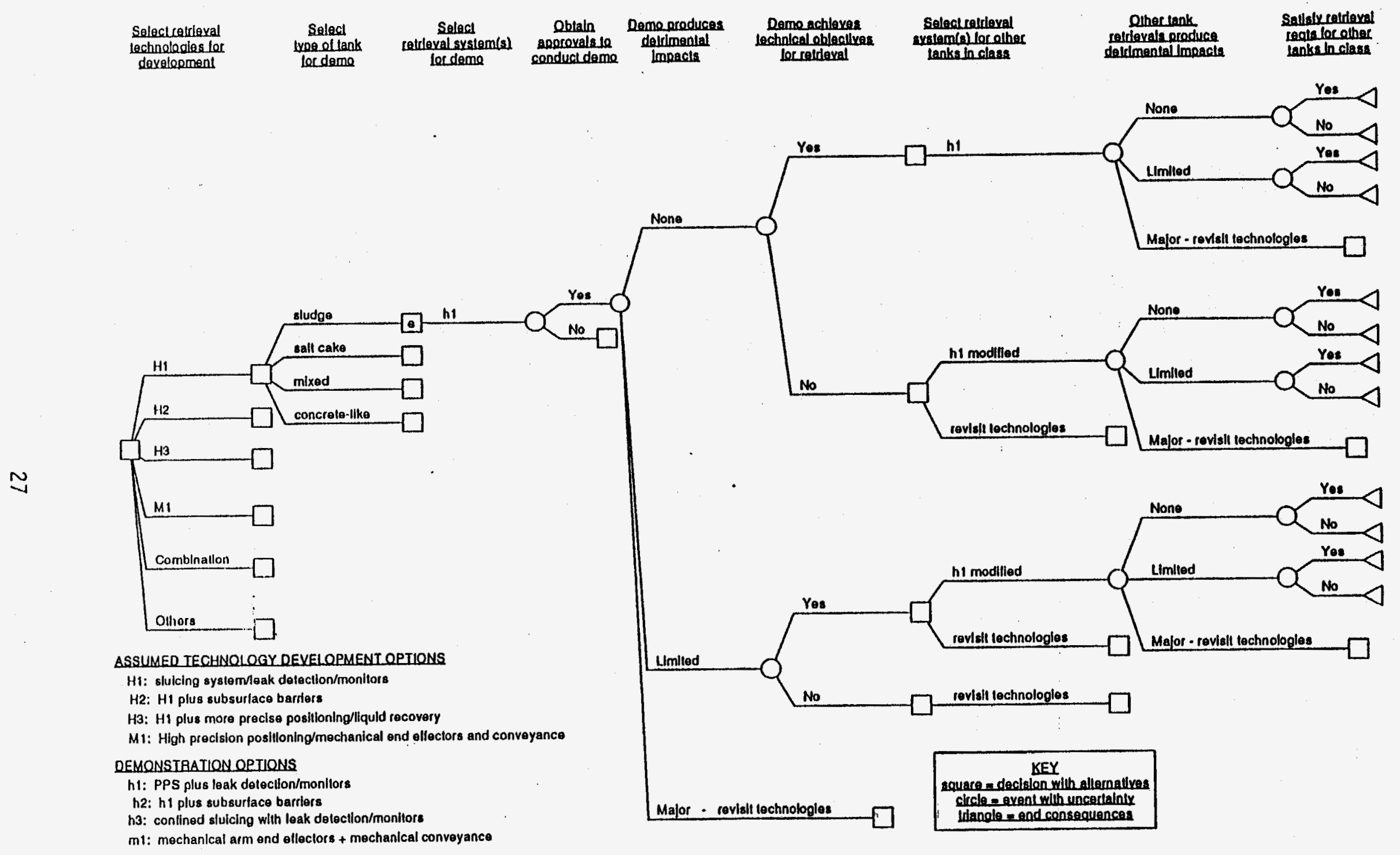

FIGURE 6-5. Decision Tree--Past Practice Sluicing Branch 


\begin{tabular}{|c|c|c|c|c|c|c|c|c|}
\hline $\begin{array}{l}\text { Selecicotuaxal } \\
\text { lechnoleoles ler } \\
\text { develeomant }\end{array}$ & $\begin{array}{l}\text { Seloct } \\
\text { troe oltank } \\
\text { loc dema }\end{array}$ & $\begin{array}{c}\text { Seleal } \\
\text { celcieval ayslem(s) } \\
\text { locdeme }\end{array}$ & $\begin{array}{c}\text { Qbjain } \\
\text { enprovalece } \\
\text { conduct deme }\end{array}$ & $\begin{array}{l}\text { Damepredicase } \\
\frac{\text { dalelmental }}{\text { Impacis }}\end{array}$ & $\begin{array}{l}\text { Deme achloves } \\
\text { Lechnlagl obleallyea } \\
\text { Iocretileval }\end{array}$ & $\begin{array}{l}\text { Soloci retcleyal } \\
\text { sxslem(s) Lor other } \\
\text { lanks In class }\end{array}$ & $\begin{array}{l}\text { Qelhes lank } \\
\text { celriavals produce } \\
\text { dedclmental limpacis }\end{array}$ & 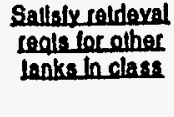 \\
\hline
\end{tabular}

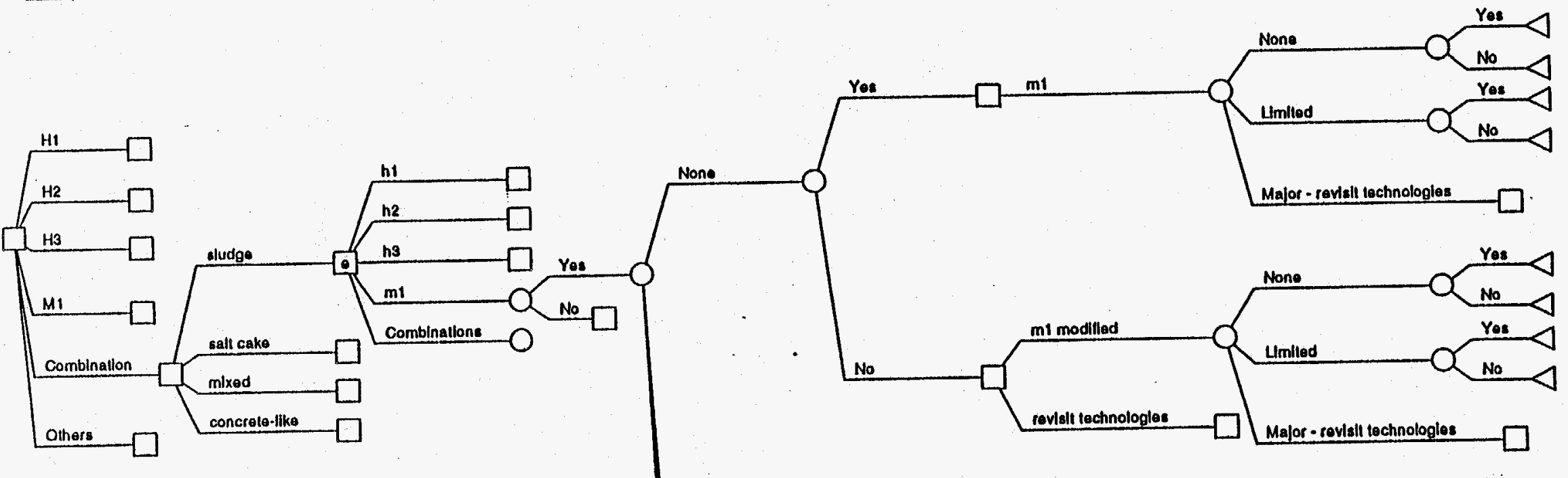

ASSUMEO TECHNOLOSTXOEXELOPMENT ORTIONS

H1: stulcing aystem/eak delection/monliors

H2: Hi plus subsurtace barriers

H3: H1 plus more preclse pasilloning/llquid recovary

M1: High preclsion posilioning/mochanical ond ellector and convoyance

\section{DEMONSTRATLONGETIONS}

ht: PPS plus leak detection/monitore

h2: hi plus subsurface barriers

h3: conlined slulcing with leak detection/monllors

m1: mechanical arm end efteclors + mechanical conveyance

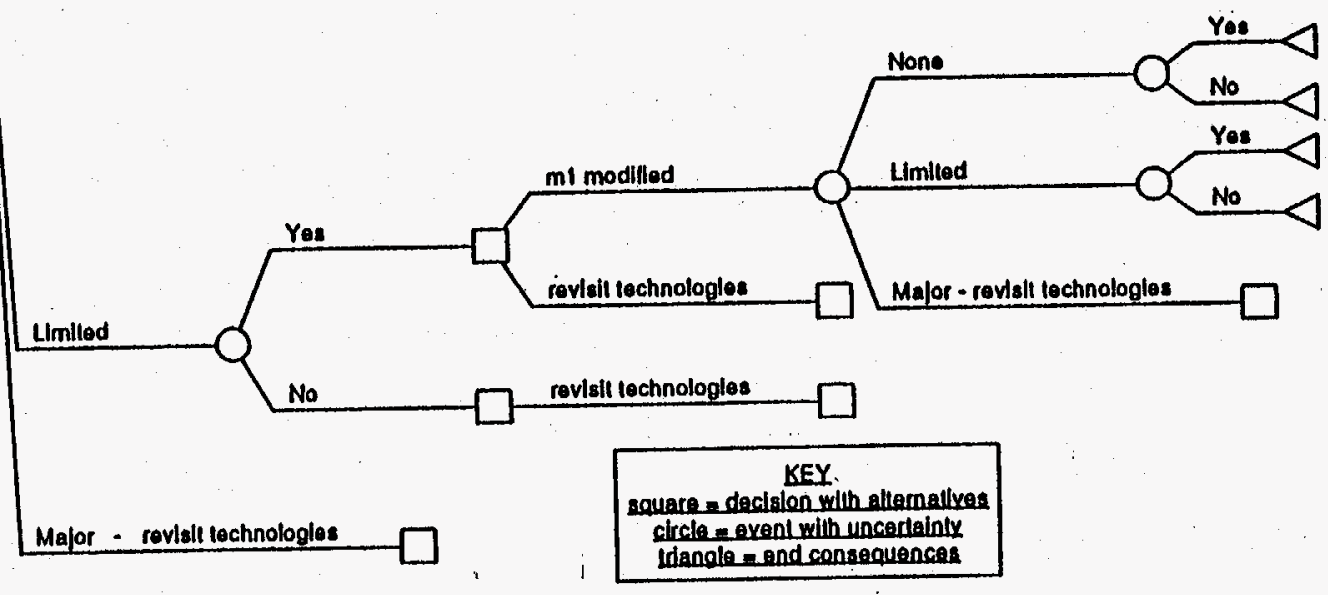

FIGURE 6-6. Decision Tree--Combination of Retrieval Technologies 
in the class may be significantly different than the uncertainties associated with the $h_{1}$ path.

Furthermore, the consequences of failure may be greater or smaller, depending on the differences in the probabilities of success for the identified uncertainties discussed in following sections. The significance of this will be discussed in a numerical example later in Section 6.7 .

\subsection{QUALITATIVE INSIGHTS FROM DECISION TREE}

There are a number of significant observations that can be derived from Figures 6-4 through 6-6:

1. There are many different success paths that can be identified starting from an initial decision to develop a retrieval system technology. The difficulty is choosing a-path which maximizes the probability of successful remediation of tanks in a class while minimizing the possibility of unacceptable detrimental outcomes.

2. For a given success path, many things must go right. That is, at each point of uncertainty (called a node in the decision tree, such as "demo achieves technical objectives for retrieval"), there must be a high probability of success in order. to ensure a high probability for overall success. For example, the top branch in Figure 6-4 shows five uncertainty nodes which have associated with them a probability of success (or failure). If one strives to obtain approvals to conduct a demonstration having no detrimental impacts, achieve the technical objectives for retrieval during the demonstration, retrieve other tanks with no detrimental impacts and satisfy retrieval requirements for other tanks in the class, then the overall probability of success would be expressed as the product of the five probabilities for success at each one of the uncertainty nodes. As will be illustrated later, if one were successful nine out of ten times at every uncertainty node, the overall probability of success for the top path in Figures 6-4 through 6-6 would be slightly less than 60 percent.

3. Not a11 "yes" paths or "no" paths are equally desirable or undesirable. For example, a detrimental impact during a demonstration which results in small amounts of leakage from a tank would be significantly less ominous than the detrimental impact that would occur if the demonstration tank should experience structural failure or a large-scale airborne release. Similarly, the "yes" path that initially results from the failure of a demonstration with its schedule delays and cost increases could prove unacceptable, despite the fact that the path could eventually lead to the successful satisfactory retrieval of waste from tanks in a class.

4. Parallel paths in technology development and even technology demonstration can significantly increase the overall chance that a class of tanks will be satisfactorily remediated with no detrimental impacts. For example, if two paths having only a 60 percent chance each of succeeding are conducted in parallel, the chance of overall success could increase to 84 percent. 
5. Figures 6-4 through 6-6 illustrate three branches of a decision tree which, when fully developed, could have as many as 72 unique yes or no outcomes, each having its own unique set of probabilities or uncertainties. This observation conveys the potential complexity of the problem and the need for a systematic method to chart decisions and document the basis for making decisions.

6. The decision analysis technique is thorough, forcing a scrutable decision process and identifying key decision points and the anticipated uncertainties that would result from these decisions.

\subsection{SIMPLIFIED QUANTITATIVE ANALYSIS}

Figures 6-7 through 6-10 show simplified versions of the decision tree originally shown in Figure 6-4. In these simplified cases, the outcomes of the decision analysis have been collected into four groups of paths. Figure 6-7 illustrates the case where every uncertainty node resulted in a yes or desirable outcome. A second path (Figure 6-8) represents the case in which particularly severe detrimental impacts occur (e.g., tank structural failure or large airborne release) during the demonstration phase of the "other tank retrieval" phase (for a given tank waste class) of the program, and the third and fourth paths (Figures 6-9 and 6-10) reflect al1 other paths in Figure 6-4, either successfut or unsuccessful. Within the third path (Figure 6-9) there are cases where satisfactory retrieval of tanks has been achieved, but at the cost of either modifying the original technology chosen for demonstration or revisiting other technologies. The fourth path (Figure 6-10) represents all those paths in Figure 6-4 which do not satisfy the retrieval requirements for other tanks in the class, yet did not result in a severe detrimental impact.

If decision-makers adopt the philosophy of maximizing the probability of a success path, while at the same time minimizing the probability of a severe detrimental impact, then one can see that the overall probability of having a successful outcome, $P_{\text {ov }}$, can be expressed as:

$$
P_{\text {ov }}=P_{1} \times P_{2} \times P_{3} \times P_{4} \times P_{5}
$$

whereas the probability of a severe detrimental impact, $P_{d}$, can be expressed as:

$$
P_{d}=P_{1} \times\left(1-P_{2}\right)
$$

The selection of appropriate values of $P_{o v}$ and $P_{d}$ is difficult. However, there is value in establishing goals for purposes of making informed decisions and driving technological development requirements. If decision-makers want to have a 98-percent probability of success and less than a one in one million chance of a severe detrimental impact, then it is clear the the average probability of success for $P_{2}$ must be greater than 0.999999 , while the probability of success for $P_{1}^{2}, P_{3}, P_{4}$, and $P_{5}$ must average at least 0.99496 and no individual probability can be less than .98--a fairly stringent or reasonable set of requirements depending on your point of view. 


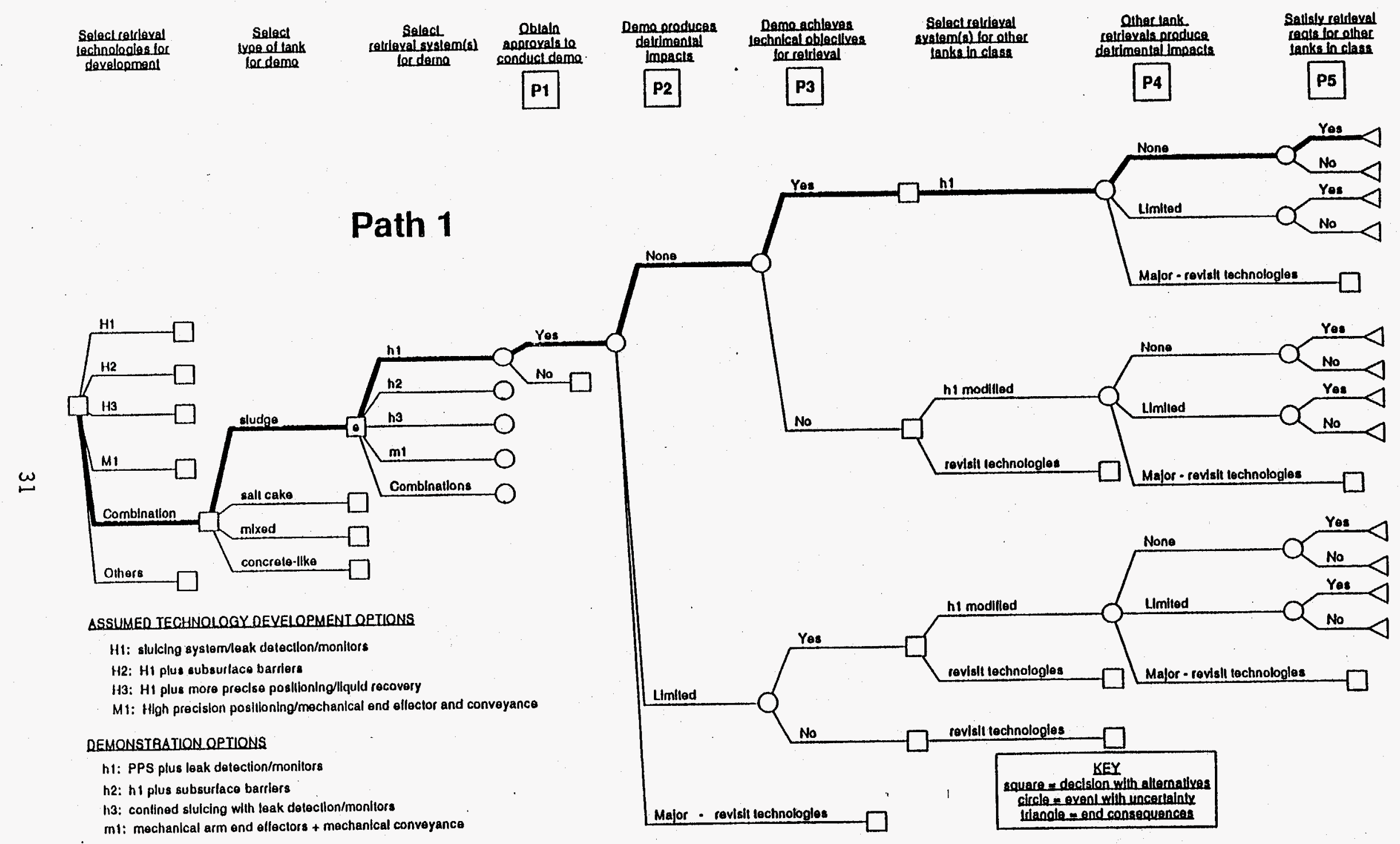

FIGURE 6-7. Path 1: Desirable Outcome--"Yes" Outcome at Every Node 


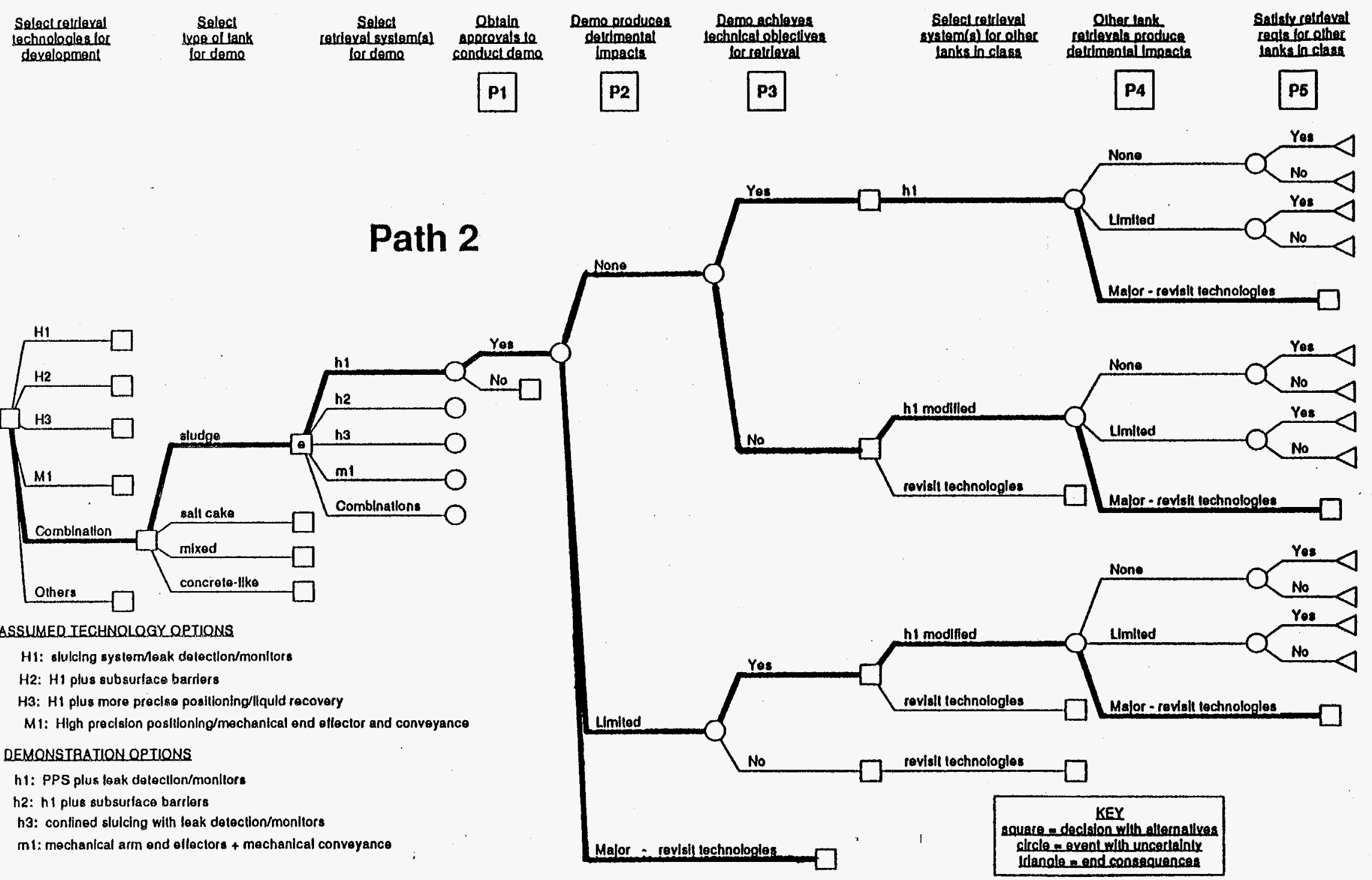

FIGURE 6-8. Path 2: Potentially Severe Detrimental Outcomes 


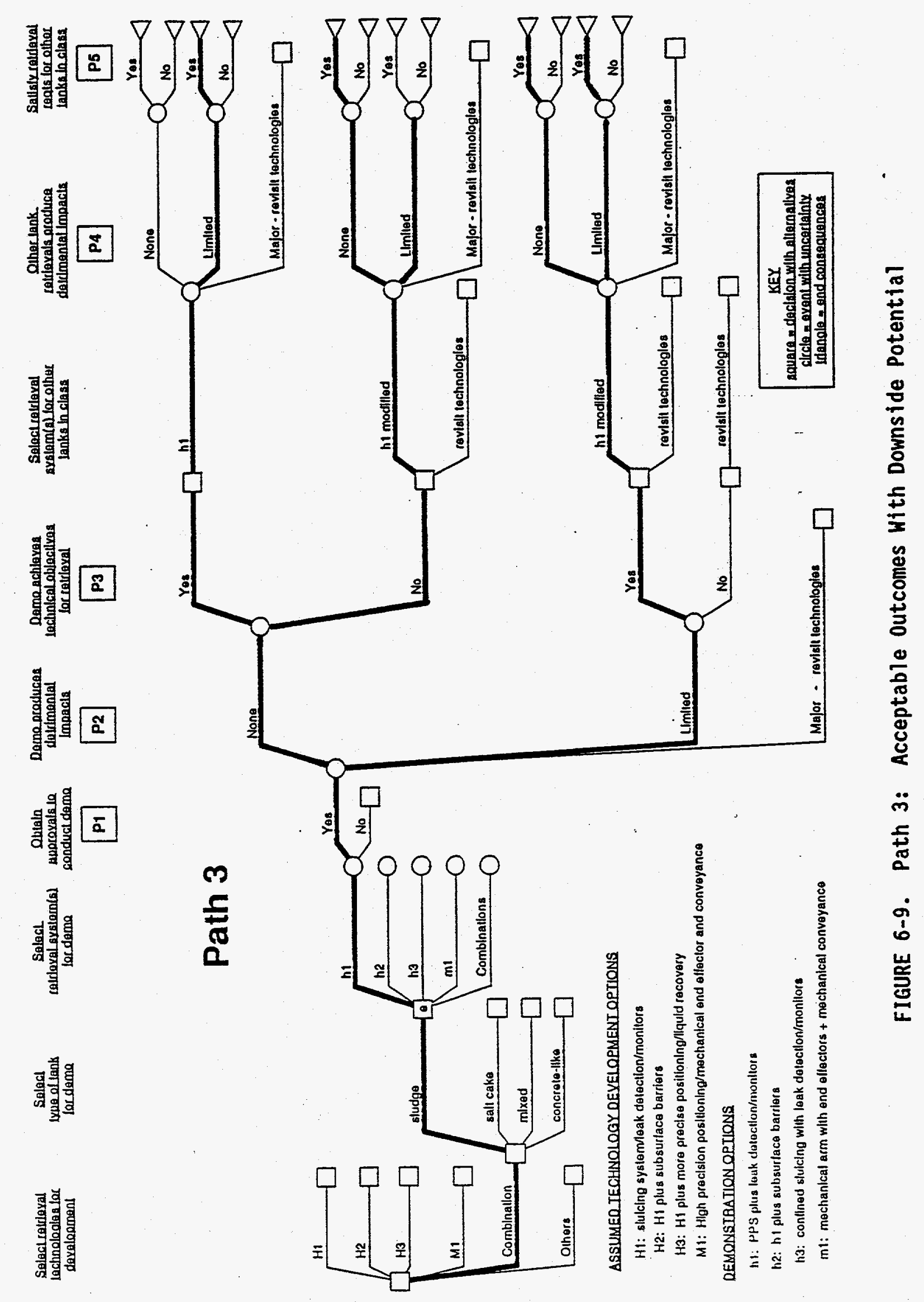




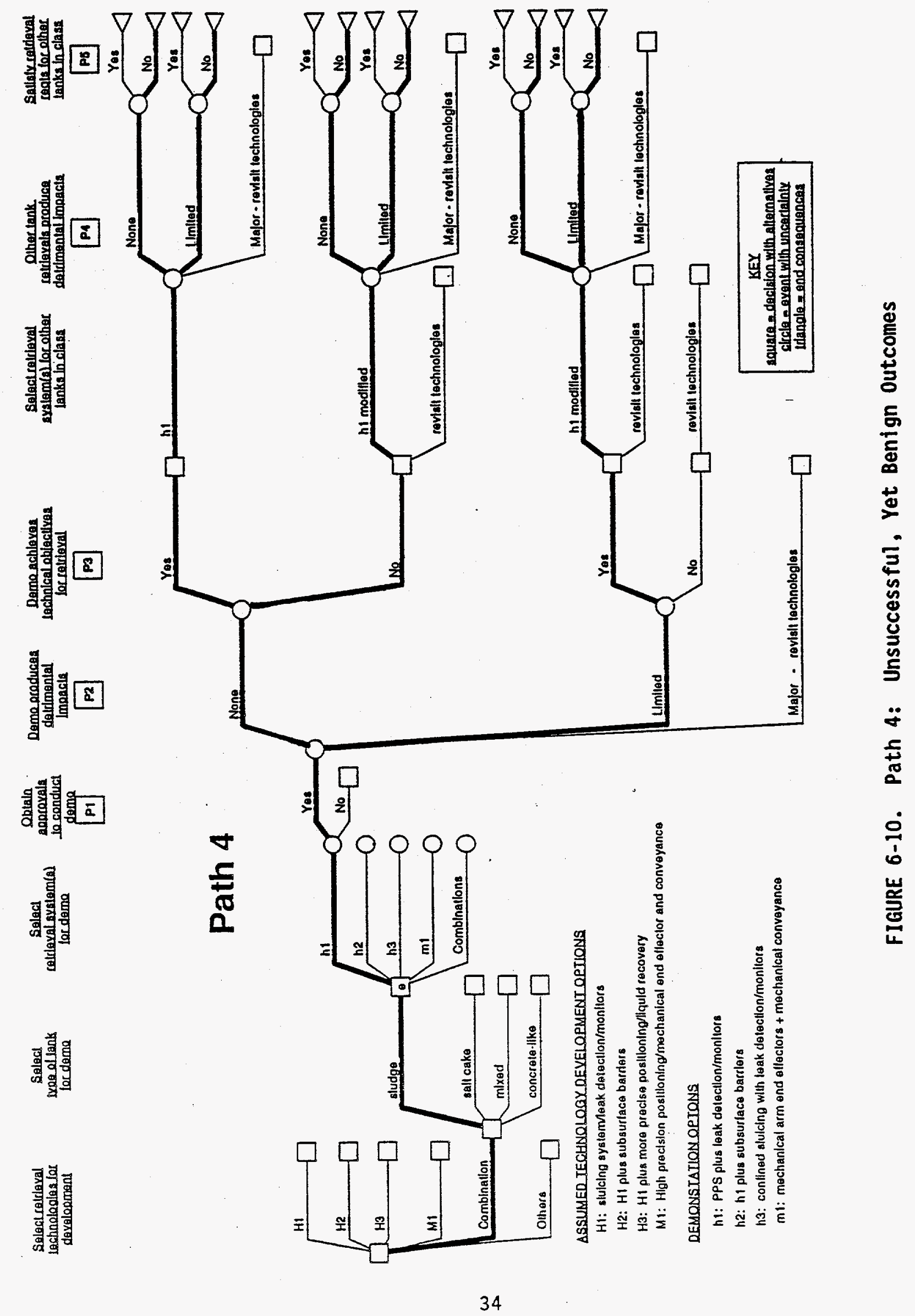


For purposes of illustration, a preliminary effort was made to present the underlying logic and factors which influence the nodes in Figures 6-7. The results of this are shown in the next section.

\subsection{ELEMENTS OF COMPREHENSIVE MULTIATTRIBUTE UTILITY ANALYSIS}

For maximum insights, accuracy, and defensibility, a full multiattribute utility analysis (MUA) of tank waste retrieval systems is recommended. Such analyses have previously been used by DOE in large, complex system programs to aid major decisions related to system and facility designs, public heaith, safety, and the environment. For example, a state-of-the-art MUA was conducted by Sandia National Laboratories to evaluate alternative designs for the Exploratory Studies Facility proposed for the potential repository site at Yucca Mountain (Dennis et a1., 1991). Lawrence Livermore National Laboratory has conducted MUAs for complex DOE systems to assist in decisions on setting priorities for major facility upgrades for nuclear material safeguards and security projects (Edmunds et 27., 1992) and for the DOE Strategic Petroleum Reserve (Fortney and Smith, 1992). Also, Los Alamos National Laboratory has conducted MUA to prioritize public health and safety actions, and DOE has used MUA to help make environmental restoration funding decisions (DOE; 1991).

A comprehensive MUA conducted with maximum rigor can be a major undertaking. Some applications have taken as much as a year to complete and required the participation of many people, including experts in MUA; yet, a rigorous and meaningful MUA could be done within a shorter schedule if it focused on addressing the aspects of one complex system, such as a waste retrieval system. However, a comprehensive MUA can substantially improve the quality of decisions, thereby helping to achieve public health, safety, and environmental objectives at minimum overall cost. It can also help enhance the defensibility of the decision process.

Conducting a comprehensive MUA of the tank waste retrieval system would require the following steps:

1. Identifying the objectives of tank waste retrieval.

2. Establishing the decision consequences that may be used to quantify the degree to which objectives are achieved.

3. Developing a decision tree to model the decisions and uncertainties that determine the decision consequences.

4. Quantifying the decision tree by estimating probabilities and consequences.

5. Calculating decision strategies that maximize expected utility and performing sensitivity analyses.

These steps are outlined below. 


\section{Step 1: Identifying Objectives}

The fundamental principle underlying MUA is that the desirability of an a]ternative is determined by the extent to which it achieves decision objectives. Thus, identifying and structuring decision objectives is the first step in a MUA.

Decision objectives are typically identified by interviewing policymakers (and, sometimes, decision stakeholders). The process of developing objectives involves two stages. First, candidate objectives are listed. Statements of objectives can often be found in applicable legislation, agency guidelines, and other documentation. The second stage in the process consists of organizing objectives into a hierarchy. Figure 6-11 shows a sample hierarchy of objectives for waste retrieval. The hierarchy defines general objectives (1ike maximizing health and safety) in terms of more specific, lower-level objectives (such as minimizing the incidence of specific types of injuries, sicknesses, and fatalities). The objectives hierarchy is recommended because its construction helps ensure that no "holes" (missing objectives) occur in the analys is and helps eliminate situations where double counting might result (because holes and redundancies are more easily identified from the hierarchy).

\section{Step 2: Establishing Decision Consequences that Measure the Achievement of Objectives}

According to the MUA approach, a means must be found for measuring the degree to which alternatives achieve objectives. This is accomplished by defining a measurement scale for each lowest-level objective in the objectives hierarchy. For example, the objective "minimize radiological health effects to workers" might be measured by total exposures expressed in person-sieverts. The measures so defined can be thought of as the consequences of decisions.

There are two types of measurement scales: natural scales and constructed scales. Natural scales are established scales that enjoy common usage and interpretation. For example, economic costs, measured in millions of dollars, is a natural scale for measuring achievement against the objective of minimizing economic costs. Constructed scales are scales developed specifically for the problem at hand. Constructed scales often consist of verbal descriptions of distinct levels of impact. For example, because there is no standard natural scale for measuring the magnitude of adverse impact of engineering activity to plants and animals, a constructed scale is needed.

\section{Step 3: Develop Decision Tree}

Figures 6-3 and 6-4 illustrate the sort of decision tree that relt be developed for an MUA of tank waste retrieval decisions. The decision tree represents the sequence of decisions that must be made and the key uncertainties that will be resolved over time. A full MUA would require refining the tree of Figure 6-4. 


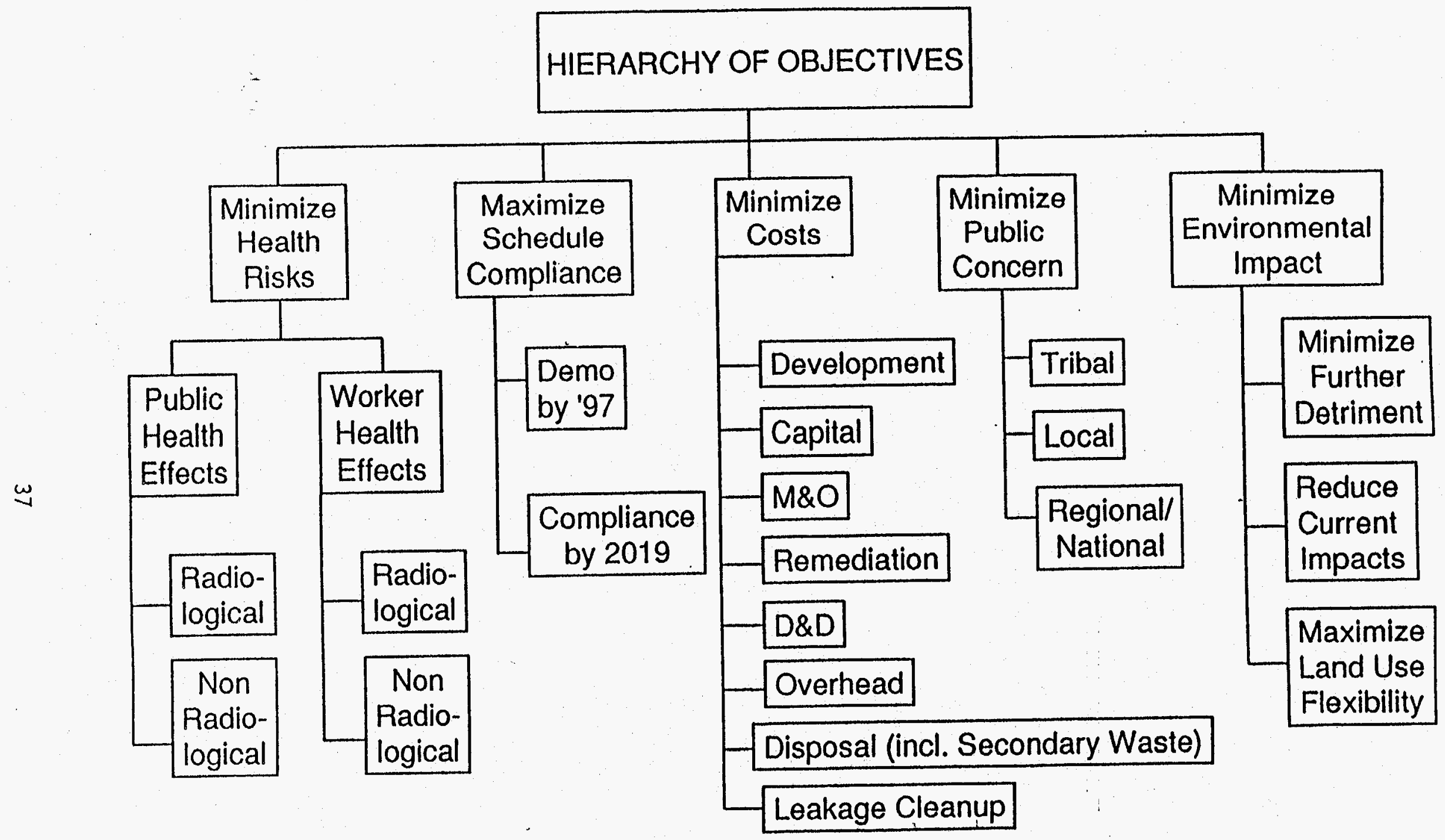




\section{Step 4: Estimate Probabilities and Consequences}

Numerous methods are available for quantifying probabilities and consequences. If sufficient data are available, statistical methods may be employed. If data are insufficient for statistical analysis, models may be constructed to estimate probabilities. Applicable existing models could be employed, or if necessary, additional models can be developed as needed. Such models need not be complicated.

Figure 6-12 illustrates an influence diagram for estimating the probability that the demonstration achieves waste retrieval requirements. Application of influence diagram models generally requires probability estimates for the model inputs. Such estimates may be obtained from statistical analysis of relevant data or through formal probability assessment methods. Probability assessment is the process of obtaining probabilities directly from knowledgeable experts. Probabilities assessed and determined by experts reflect their professional judgement, taking into consideration all models, data, and other applicable resources at their disposal. The arguments supporting the use of probability assessment in MUA derive from theory and experimental results that show that judgements about uncertain events can be expressed as probabilities. Considerable research has been conducted to develop probability assessment procedures that reflect an expert's judgement while minimizing bias (Tversky and Kahneman, 1984).

The standard probability assessment process is conducted as a joint undertaking by a trained probability assessor and an individual who is expert in what is known and unknown about the uncertain quantity to be assessed (Merkhofer, 1987; Spetzler. and Stael von Holstein, 1975; Stael Von Holstein and Matheson, 1979; Bonano et a1., 1990). The assessment process consists of several phases in addition to the actual quantifications of the judgements by experts in probabilistic terms. These steps are designed to help the assessor identify and reduce the effect of cognitive and motivational biases held by the subject ("conceptual biases") and biases that might be introduced by the assessment method ("task biases").

An approach used in previous DOE applications of MUA is to obtain the probabilities needed for a decision tree directly as consensus, judgmental estimates generated by expert panels. To support panel deliberations, influence diagrams are used. Specifically, the expert panel responsible for the estimate develops an influence diagram summarizing the factors and features of an option that influence the probability to be estimated. The lowest-level (i.e., most detailed) factors in the diagram are used to generate comparative evaluation questions. Each panel member is then asked to estimate how well each option would perform with respect to each factor and to rank the options with respect to that factor. The various rankings are then aggregated, across panel members, to obtain rankings of the options with respect to each factor in the relevant influence diagram. Finally, the quantitative rankings are aggregated across factors to obtain an overall ranking with respect to the probability described by the influence diagram. This overall ranking is then used by panel members to guide the assignment of probabilities.

To illustrate the approach, the IRG used the influence diagram of figure 6-12 to generate judgmental probability estimates of probability $P_{3}$ in the decision tree (probability that the selected technology for the demonstration 


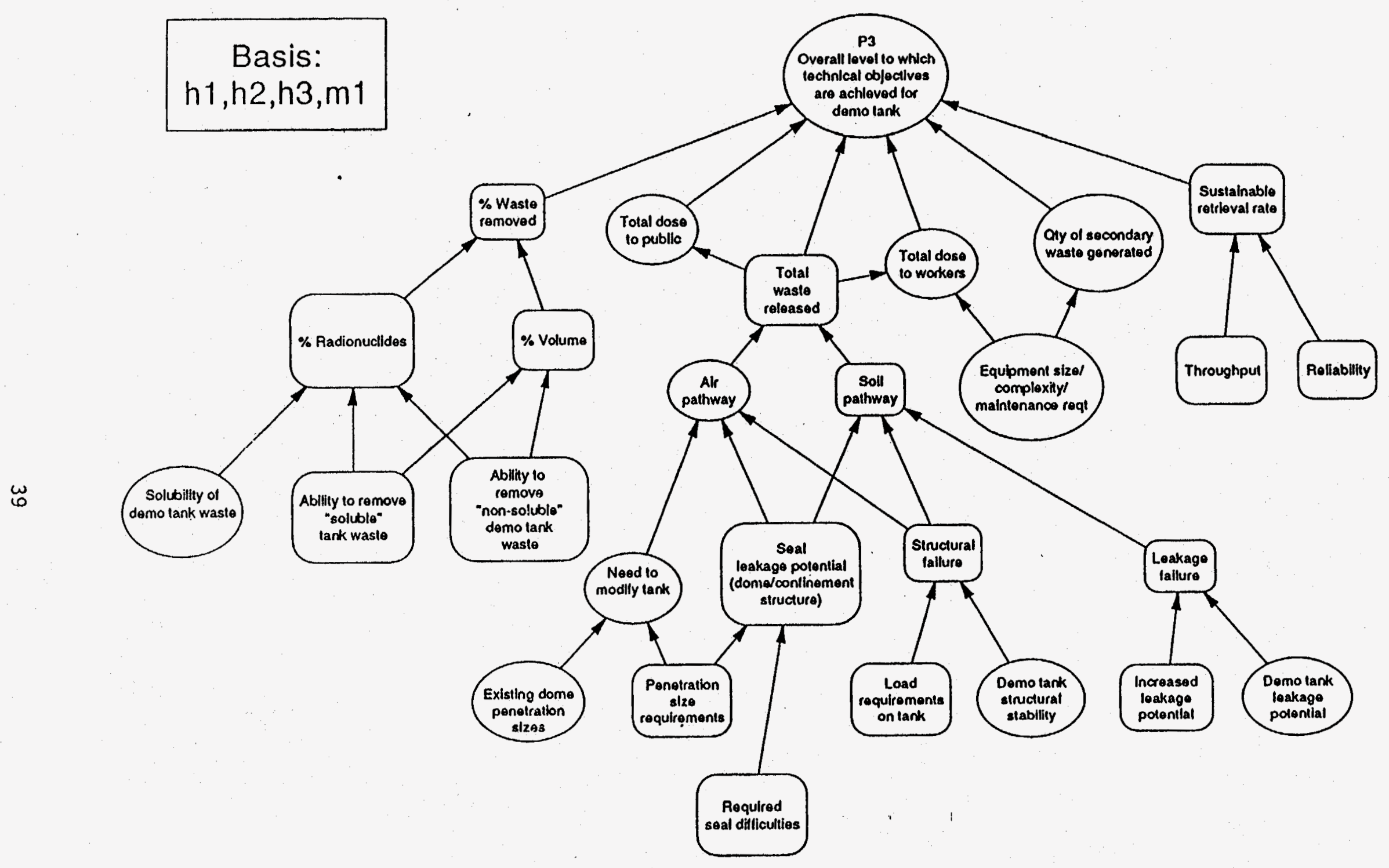

FIGURE 6-12. Influence Diagram 
would achieve technical success). First, the IRG identified a subset consisting of the lowest-level factors in the diagram that were judged to be the most important discriminators. These factors are distinguished in the diagram as rectangular (rather than oval) nodes. Each IRG member then ranked the options, from best to worst, with respect to technology penetration size requirements. The various rankings provided by IRG members were in close agreement.

The decision trees used to illustrate the evaluation process contain five probabilities that need to be estimated for each retrieval system technology $\left(h_{1}, h_{2}, h_{3}, m_{1}\right.$, or a combination) and for each waste tank class (sludge, salt cake, mixed or concrete-like). These five probabilities are denoted $P_{1}, P_{2}$, $P_{3}, P_{4}$, and $P_{5}$ (see Figures 6-7 through 6-10 for relationship to decision tree). To estimate such probabilities, some type of a formal systematic process is necessary. Two different approaches, fault trees and influence diagrams, were examined. These approaches identify, assess, and summarize the factors and features of a waste retrieval system that influence or contribute to the estimate of the probability.

Figure 6-12 shows an influence diagram developed to facilitate the assessment of the probability, $P_{3}$, that the technical objectives are achieved for the waste retrieval from the demonstration tank. This probability can also be dependent upon the outcomes of the preceding probabilities in the decision tree, $P_{1}$ and $P_{2}$.

An influence diagram is a graphic representation of the relationships among factors that influence a performance measure, in this case a probability. Figure 6-12 was developed by the IRG during a group session as a typical example for the problem to be addressed as described in this segment of the decision tree. To develop the diagram, IRG members identified factors that in their best judgement would influence the likelihood of succeeding in the achievement of these technical objectives. With a session facilitator, the factors were then organized into an assembly that was logically ordered in terms of their influence and hierarchy. The highest-level node, or "bubble," in the diagram of Figure 6-12 represents the probability, $P_{3}$, of the success of achieving the technical objectives of the demonstration. The connected sequences of the smaller bubbles and rectangles in Figure 6-12 contain the factors judged to influence the probability estimate. The factors in the lowest-level bubbles are identifiable aspects, or features, of the individual retrieval system alternatives. The factors in the rectangles were judged to provide the most significant basis for discriminating between and among the retrieval system alternatives in terms of the likelihood of successfuliy achieving the technical objectives for the waste retrieval demonstration.

For Figure 6-12, the most significant discriminating factors were judged to be the percentage of waste removed during retrieval, the amount of total waste released through ths :0il pathway, and the sustainable waste retrieval rates. Three of the six tactors with arrows drawn directly to the uppermost bubble were viewed as the most discriminating and are shown as rectangles. other of the factors at the lower level were developed for the alternative retrieval system technologies being assessed. The development of Figure 6-12 assumed that a sludge tank type was selected for the waste retrieval demonstration and also assumed the illustrative decision tree discussed earlier. 
With the development of this influence diagram, the following section discusses the development of a quantitative probability estimate for $P_{3}$. The individual rankings provided by each IRG member were averaged to obtain the results shown in Table 6-1 (a tie between two technologies is denoted by assigning the same ranking to each--e.g., $h_{1}$ and $h_{2}$ were both assigned a numerical value of 1 in the first row of the table because they were judged to be equal and best with respect to ability to remove "soluble" waste). The consensus judgement among IRG members was that $h_{1}$ was best (or tied for best) with respect to all factors except (1) ability to remove "non-soluble" waste and (2) increased leakage potential. Taking into account the rankings and the relative influence of the factors on technical success, the panel provided the overall ranking shown in the table. This ranking was then used by the panel as a guide to the assignment of a probability of technical success to each technology. The results are shown in the table. As indicated, the IRG concluded that each technology has a high probability of achieving technical success (assuming no detrimental impacts). The differences between the estimates are relatively smal1; however, the highest probability (97 percent) of technical success was assigned to $h_{1}$.

A similar approach could be used to obtain estimates for the other probabilities needed by the decision tree. By constructing influence diagrams for the other probabilities, a systematic process for generating judgmental probability estimates would be provided. To illustrate some of the considerations relevant for estimating the probability of various levels of detrimental impacts, a portion of an influence diagram for detrimental impacts to heip define $P_{2}$ was developed. This diagram is shown in Figure 6-13. As indicated, various levels of impact (none, 1 imited, or major) may be associated with various types of events (e.g., schedule slippage or cost overruns may produce limited impacts; tank structure failure or large off-site releases may produce major impacts).

For the other probabilities, $P_{1}, P_{3}, P_{4}$, and $P_{5}$ in the decision trees shown in Figures 6-7 through 6-10, similar assessments of factors attributable to these node points need be considered and individual influence diagrams developed in order to determine the considerations to be addressed in the estimate of these other probabilities.

To develop the probability, $P_{5}$, that of satisfying all retrieval requirements for other tanks in the same waste class, a starting point would be to modify the influence diagram as shown in Figure 6-12. Some important factors in the influence diagram for aiding in the determination of $P_{5}$ are: (1) total radiation dose to the public, (2) total dose to workers, and (3) quantity of secondary wastes generated.

Although the basic meaning of the symbols and significance would be similar to those described for Figure 6-12, the descriptive terms for the factors shown as bubbles and rectangles, and their number, would differ for the $P_{5}$ in comparison with the influence diagram for $P_{3}$. Because an influence diagram is developed from the top to the bottom, the lower-level factors important to estimating the probability, $P_{5}$, would also change. A new 
TABLE 6-1.

Ranking of Technologies with Respect to Factors Influencing the Probability of Achieving Technical Success in the Demonstration

Group Average

\% Waste 1) Ability to remove "soluble" waste

Removed

2) Ability to remove "non-soluble" waste

\begin{tabular}{|c|c|c|c|}
\hline $\mathrm{h} 1$ & $\mathrm{~h} 2$ & $\mathrm{~h} 3$ & $\mathrm{~m} 1$ \\
\hline 1.0 & 1.0 & 3.0 & 4.0 \\
\hline 3.0 & 3.0 & 2.0 & 1.0 \\
\hline 1.0 & 1.7 & 2.7 & 4.0 \\
\hline 1.0 & 1.0 & 3.0 & 3.7 \\
\hline 1.0 & 2.3 & 2.7 & 3.7 \\
\hline 3.7 & 2.7 & 2.3 & 1.0 \\
\hline 1.0 & 1.7 & 2.3 & 3.7 \\
\hline 1.0 & 2.3 & 2.7 & 4.0 \\
\hline
\end{tabular}

Overall Rank

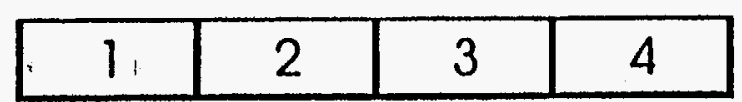

Overall Probabilityof Achleving

\begin{tabular}{|l|l|l|l|}
\hline 0.97 & 0.94 & 0.91 & 0.86 \\
\hline
\end{tabular}


influence diagram for $P_{5}$ could be developed in similar process as for $P_{3}$, which then could be quantified.

To develop the probabilities that the demonstration produces detrimental impacts, $P_{2}$, and that the retrieval of wastes from a 11 tanks in the same class produces detrimental impact, $P_{4}$, assessments similar to those for $P_{3}$ and $P_{4}$ would be necessary. Some factors that would need to be assembled into an influence diagram and assessed include public radiation exposures, worker exposures, environmental impacts, cost, schedules, potential accidents, and others. Figure 6-13 shows how an influence diagram for $P_{2}$ might be arranged.

A well crafted and thoughtful effort is necessary throughout the analyses. Expert judgement and verification is necessary to estimate the probabilities and uncertainties for each of the factors in the decision tree. Although, in some cases, such a test would require a more demanding and rigorous effort, the structure of the decision tree allows for a wide range of sensitivity analyses to be conducted and provides guidance to decision-makers who choose a specific course of action and need to defend those choices. The indefensibility will be aided as a result of employing this systematic process, decision analysis, which will provide a documented record of factors considered as well as credibility for the rigorous analyses that were included in the decision-making.

\section{Step 5: Calculate Utility, Solve the Decision Tree, and Conduct Sensitivity Analyses}

The final step in MUA begins by aggregating the various consequence measures to obtain the overall utility of each path through the decision tree. This step requires developing a multiattribute utility function. The multiattribute utility function is an equation that combines the various consequence measures in a way that accounts for value judgements. For example, if the consequence measures pass certain independence tests, an additive equation is appropriate. With the additive equation, value judgements amount to specifying "tradeoff weights" that convert each consequence measure to a common unit, which allows them to be added to obtain a measure of overall utility. The value judgements necessary to specify the multiattribute utility function are typically elicited from expert panels using formal assessment methods (Keeney, 1977). Utility functions can also account for other value judgements, such as attitudes toward accepting risk. Once consequences have been converted to utility, the tree is solved. Solving a decision tree involves computing expected utilities for each node in the tree by multiplying the utilities associated with each branch times the probability of the branch and adding the results. At decision nodes, the choice resulting in the highest expected utility is chosen. Thus, solving the decision tree not only identifies the best initial decision for the tree (e.g., which retrieval technologies should be developed), it also provides a contingency strategy for making future choices (e.g., which technologies to use for remaining tanks depending on the outcome of the initial tank demonstration). Other standard outputs include probability distributions describing the uncertainties over the consequences of each strategy (e.g., uncertainty over cost, schedule, health effects, and so forth).

Figure 6-14 provides an illustrative example of this type of output. The curves represent cumulative probability functions. With a cumulative 


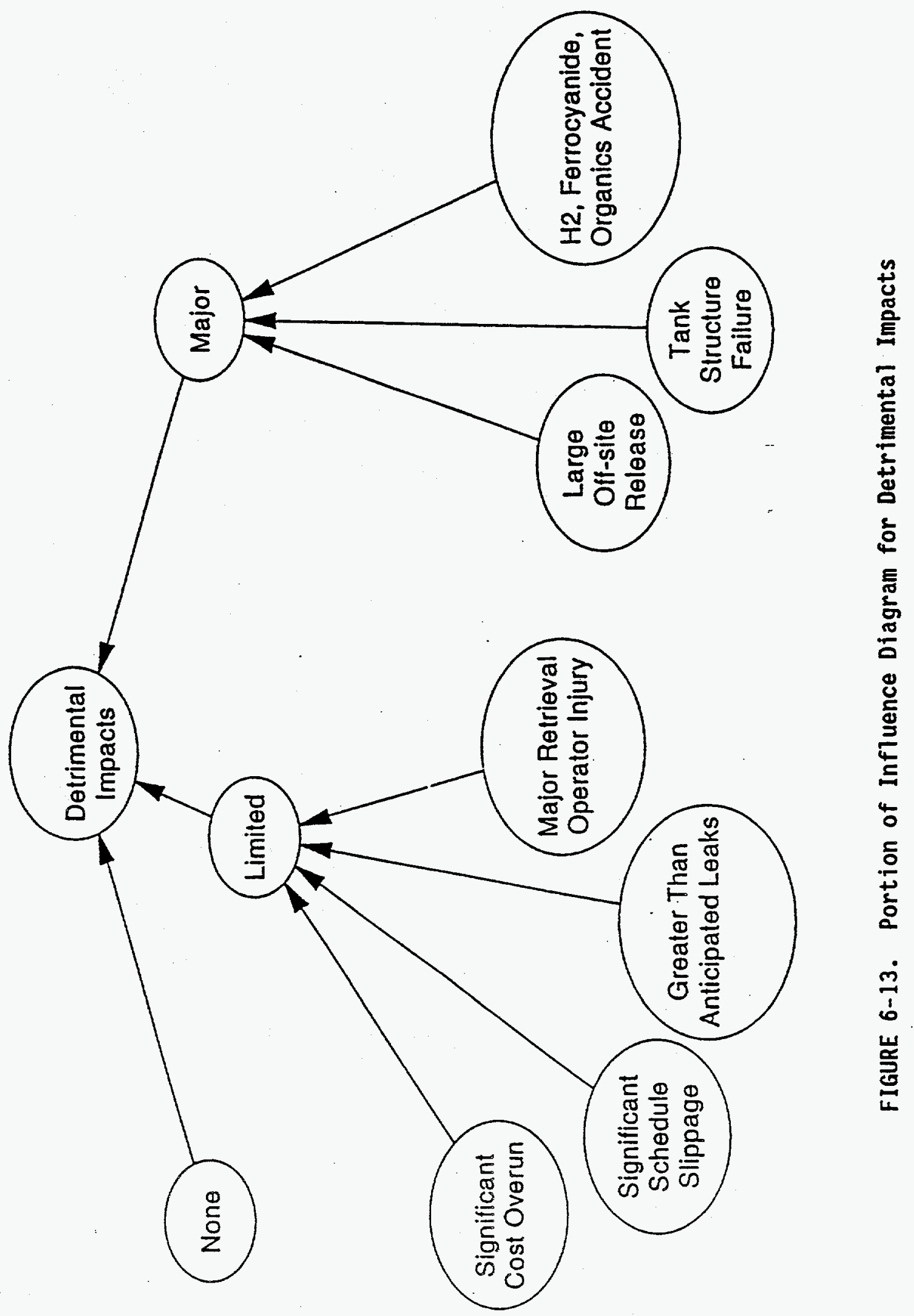


probability function, the height of the curve on the $y$-axis indicates the probability of obtaining values of an uncertain quantity less than or equal to the corresponding value on the $x$-axis. The example illustrates two alternatives for how uncertainty over costs might appear. Example Curve $A$ rises steeply until a cumulative probability of about 95 percent and then flattens out with a long "tail." The interpretation is that costs will be contained within the indicated cost $C$ with 95-percent probability, but there is a 5-percent probability of costs being nearly twice again as high. Example Curve $B$ rises more gradually, but spans roughly the same range of costs. With Curve $B$, there is a 50-percent probability that costs will exceed the indicated cost $C$. The shape of such cumulative probability curves and the range that they cover says much about the nature of existing uncertainties. The cost uncertainties actually obtained from MUA might appear very different; however, the nature of cost and other uncertainties could be similarly clarified through the generation of such uncertainty curves. Finally, the quantified decision tree may be used to compute the value of collecting information to resolve uncertainties before committing to a decision.

The final step in the MUA process is to conduct sensitivity analyses. Figure 6-15 illustrates how sensitivity results might be displayed. In a sensitivity analysis, each parameter or input to the analysis is varied across a range of values that represent uncertainty or differences of opinion regarding that quantity. Sensitivity analyses are used to explore whether the basic conclusions of the analysis are independent of specific assumptions or estimates that have been made. Often times, sensitivity analysis indicate that key conclusions are independent of controversial assumptions. For example, individuals may disagree over what weights to use in the multiattribute utility function. However, analyses often indicate that detailed conclusions do not vary over a wide range of possible weights. For example, in the recent MUA of designs for the Exploratory Studies Facility for Yucca Mountain, the ranking of design options was found to be completely independent of the weights used in the multiattribute utility function (Dennis, 1991). Such sensitivity results can be used to focus debate away from disagreements that do not affect decisions.

\section{Benefits of an Multiattribute Utility Analysis Approach}

Al though numerous less rigorous methods might be used to evaluate tank waste retrieval systems, a complete MUA is likely to be the most appropriate method. The use of evaluation methods less rigorous than formal decision analysis may seriously damage the credibility of the decision-making process and necessitate a follow-up evaluation based on MUA. This has happened before. For example, DOE initially used simple weighing and scoring methods to rank alternative sites for the high-level nuclear waste repository and published the analysis in 1984 in the draft environmental assessments for the candidate sites (DOE, 1986a). Numerous criticisms of the approach were received, including a letter from the National Academy of Sciences (NAS) that called the methods "unsatisfactory, inadequate, undocumented, and biased." Responding to these criticisms, DOE subsequently conducted a comparative evaluation of the sites using MUA (DOE, 1986b). The Board on Radioactive 


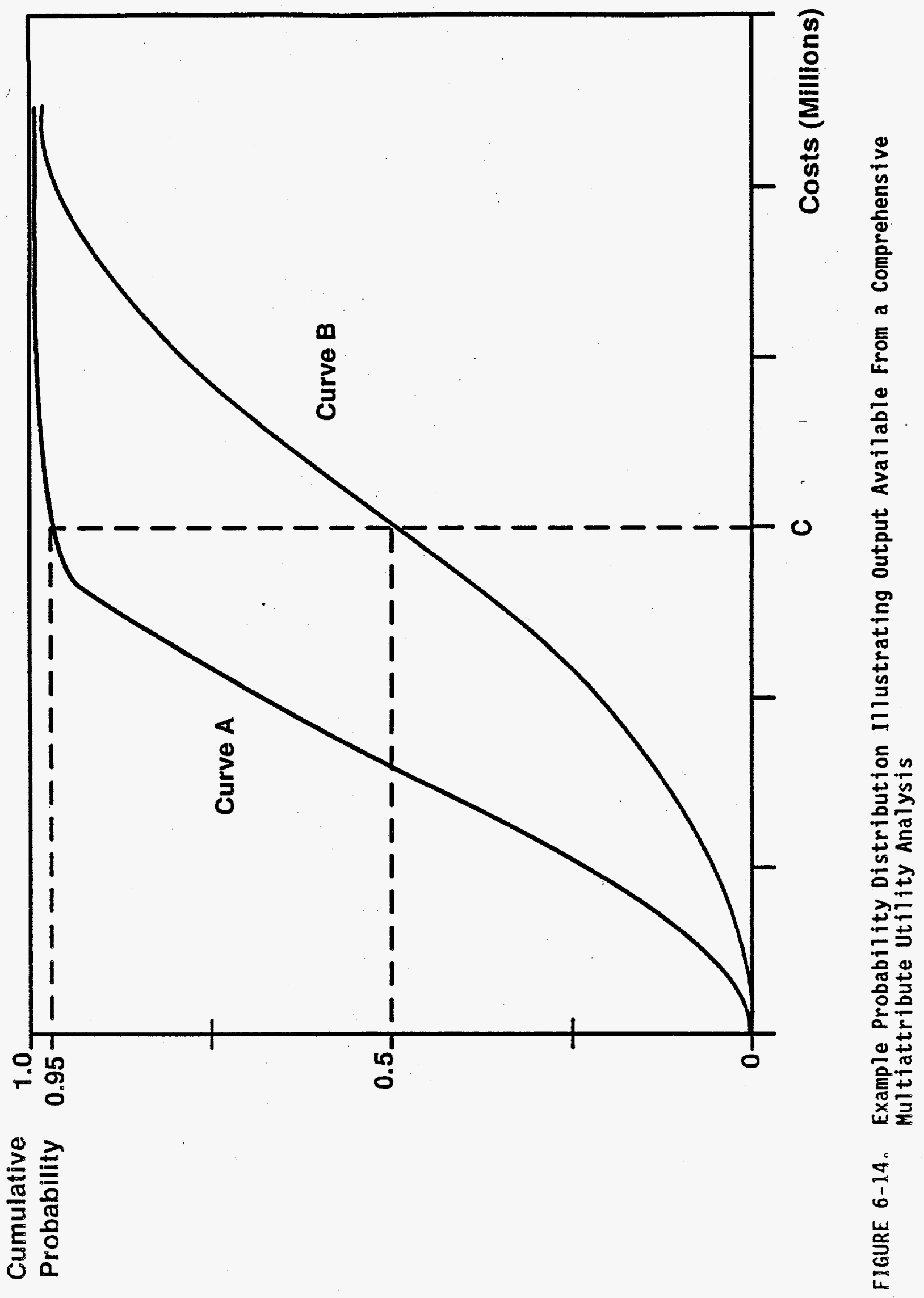




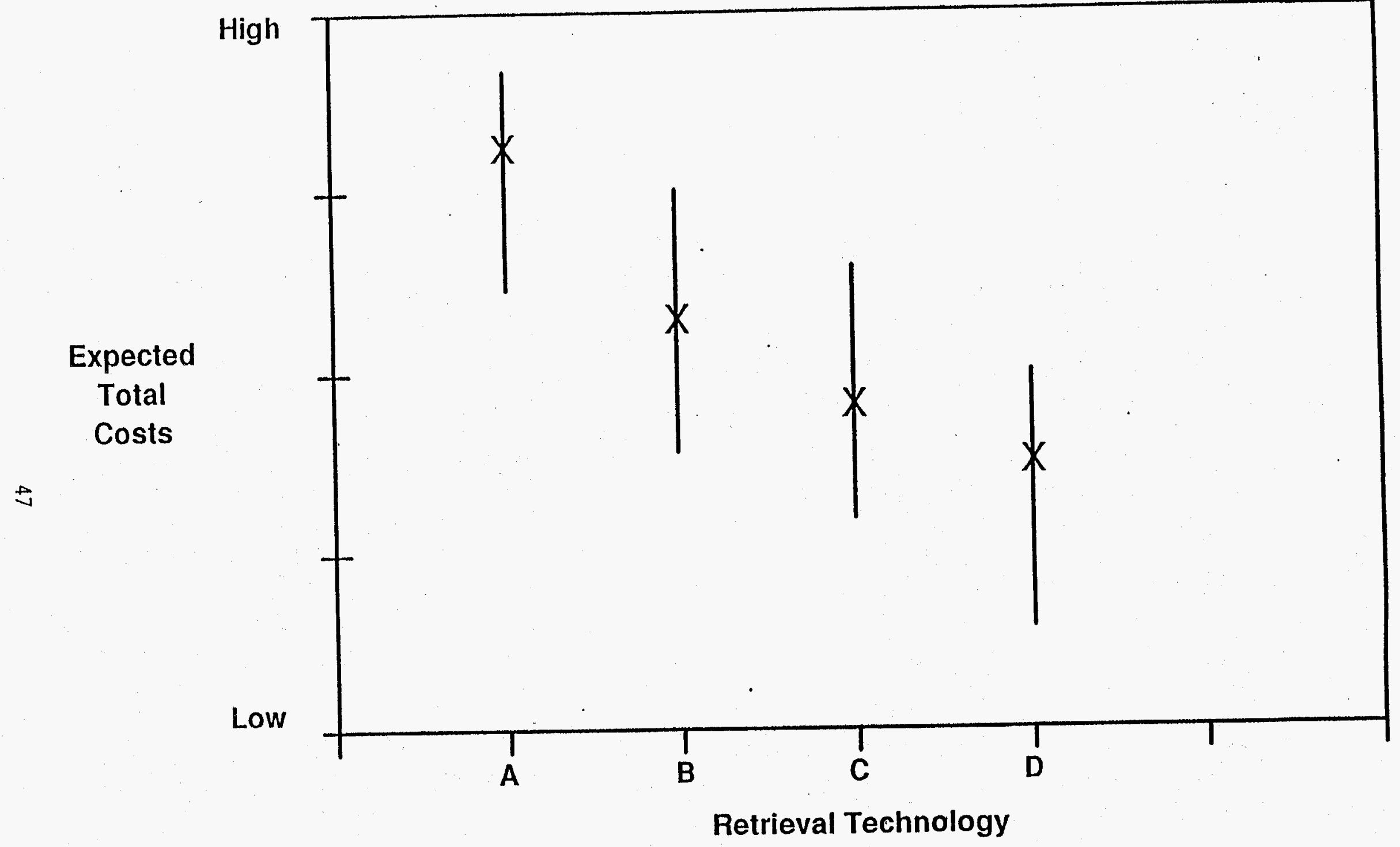

FIGURE 6-15. Example Illustrating Sensitivity Output Available From a Comprehensive Multiattribute Utility Analys is 
Waste Management of the NAS was invited to review the methodology. The Board concluded:

"The use of the multiattribute utility method is appropriate, and the Board is impressed by the care and attention to detail with which it has been implemented . . the Board believes that the multiattribute utility method used by DOE is a satisfactory and appropriate decision-aiding tool ...

Similar conclusions have been reached in other recent applications of MUA to hazardous waste decisions. For example, an independent technical review group was established to review DOE's choice of MUA as a method for prioritizing environmental cleanup activities. They concluded (Burke et al., 1991):

"The (DOE ER Priority) system is well-designed, technically competent, appropriate to its purpose, and ready to use .... The key to the systems's design is its explicit acceptance of multiattribute utility analysis as the best approach to such complex prioritization problems. The tool fits the problem very well." 


\subsection{KEY INSIGHTS, CONCLUSIONS, AND RECOMMENDATIONS}

Our development of a tool for evaluating waste retrieval systems has led to the following insights and recommendations. In addition to the systems analysis approach used in this IRG assessment, we evaluated a decision analysis. technique as a potential means of selecting retrieval technologies.

\subsection{KEY INSIGHTS}

1. Many retrieval options can be identified. The difficulty is choosing one most likely to be successful and least likely to have a detrimental outcome.

2. For a selected retrieval option, many things must go right. That is, at each point of uncertainty there must be a high probability of success to ensure overall success.

3. Not all "yes" or "no" options have decision choices and outcomes that are equally desired. For example, small amounts of leakage from a tank during a demonstration would have a less detrimental impact than an airborne release.

4. Parallel paths in technology development--and even in demonstrations--increase the chances of successful remediation.

5. When the three branches of the decision tree initially outlined by the IRG are fully developed, there could be as many as 72 "yes" or "no" outcomes, each with its own set of probabilities. This observation conveys the complexity of the problem and the need for a method of charting decisions and documenting the basis for making them.

6. The decision analys is technique is thorough, forces a scrutable decision process, and identifies the key decision points and the anticipated uncertainties that follow decisions.

\subsection{KEY CONCLUSIONS AND RECOMMENDATIONS}

1. Systems and decision analysis techniques need to include:

- Credible and documented decision logic.

- Evaluations in which retrieval technologies are matched with tank wastes classified by contents.

- Measurements of uncertainties and the relative worth of system factors.

- Quantitative analyses.

- A converging set of outcomes as focused input in decision-making. 
2. SSTs and DSTs should be classified by their contents. This classification would be used to determine retrieval technologies. It would be similar to the mappings seen in the monthly report series Tank Farm Surveillance and Waste Status Summary Report (WHC-EP-0182-XX).

3. Methods are available for quantifying probabilities and consequences. The use of such methods would heighten the credibility of these key measures in decision analysis.

4. Quantified decision trees may be used to compute the value of collecting information to resolve uncertainties before committing to a decision.

5. Sensitivity analyses can be used with decision analyses to show that certain key conclusions may be independent of controversial assumptions. The debate could then be focused away from disagreements that do not affect decisions.

6. Two important groups have endorsed the use of decision analysis in making hazardous waste decisions: (1) the Board on Radioactive Waste Management of the National Academy of Sciences, and (2) an independent technical review group established by DOE to prioritize environmental cleanup activities. The first group states that decision analysis is an "appropriate decision-aiding tool." The second group calls decision analysis the "best approach to such complex prioritization problems" 'which "fits the problem very we11."

7. We highly recommend a detailed and focused decision analys is of tank waste retrieval systems. Such an analysis would provide insight, accuracy, and defensibility. 


\subsection{REFERENCES}

Belton, V., and T. Gear, "On a Short-Coming of Saaty's Method of Analytic Hierarchies," Omerga, 11(3), pp. 228-230, 1983.

Boomer, K. D. (Team Leader), "Systems Engineering Study for the Closure of Single-Shell Tanks," WHC-EP-0405, Richland, WA, August 1991.

Bonano, E. J., S. C. Hora, R. L. Keeney, and D. von Winterfeldt, "Elicitation and Use of Expert Judgement in Performance Assessment for High-Level

Radioactive Waste Repositories," NUREG/CR-5411, SAND89-1821, prepared for U.S. Nuclear Regulatory Commission (by) Sandia National Laboratories, NRC, Washington DC, May 1990.

Bunn, D. W., Applied Decision Analysis, McGraw-Hil1, New York, NY, 1984.

Burke, T., J. Dyer, W. Edwards, K. Hutebak, N. Matalas, H. Messner, F. Parker, G. Paulson, C. Russel, M. Russel, and R. Zeckhauser, "Executive Summary of the Report of The Technical Review Group of the Department of Energy's Priority System for Environmental Restoration," Washington, DC, Apri1 17-18, 1991.

Dennis, A. W. (editor) "Exploratory Studies Facility Alternatives Study, Volume 2: A Comparative Evaluation of Alternative Exploratory Studies Facility Options," SAND91-0025/2. UC-814, prepared for the U.S. Department of Energy by Sandia National Laboratories, Albuquerque, NM, 1991.

DOE (U.S. Department of Energy), "Draft Environmental Assessment, Reference Repository Location, Hanford Site," DOE/S-0048, Office of Civilian Radioactive Waste Management, Washington DC, 1986a.

DOE (U.S. Department of Energy), "A Multiattribute Utility Analysis of Sites Nominated for Characterization for the First Radioactive-Waste Repository--A Decision-Aiding Methodology," DOE/RW-0074, Office of Civilian Radioactive Waste Management, Washington DC, $1986 \mathrm{~b}$.

DOE (U.S. Department of Energy), "Preliminary Design Report: A Formal Priority System for Environmental Restoration, "Office of Environmental Restoration, Washington DC, 1991.

Dyer, J. S., "Remarks on the Analytic Hierarchy Process," Management Science, $36(3)$, pp. 249-258, 1990.

Edmunds, T. A., R. A. Saleh, and S. L. Zevanove, "Prioritizing and Scheduling Portsmouth Gaseous Diffusion Plant Safeguards Upgrades, " UCRL-ID-109587, Lawrence Livermore National Laboratory, Livermore, CA, December 1991.

Fortney, D. S., and G. R. Smith, "An Approach for Consequences Evaluation and an Application to the Strategic Petroleum Reserve, "UCRL-JC-110103, Lawrence Livermore National Laboratory, Livermore, CA, July 1992.

Harker, P. T., "Incomplete Pair-Wise Comparisons in the Analytic Hierarchy Process," Mathematical Modeling, 9(11), pp. 837-848, 1987. 
Hobbs, B. F., "Analytical Multi-Objective Decision Methods for Power Plant Siting: A Review of Theory and Applications," NUREG/CR-1687, BNL-NUREG-51204, prepared for the U.S. Nuclear Regulatory Commission \{by\} Brookhaven National Laboratory, Uptown, NW., 1979.

Howard, R. A., "The Foundations of Decisions Analysis," IEEE Transactions on Systems Science and Cybernetics, SSC-4(3), pp. 211-19, 1968.

Keeney, R. L., "The Art of Assessing Multiattribute Utility Functions," Organizational Behavior and Human Performance, 19(2), pp. 267-310, 1977.

Keeney, R. L., and H. Raiffa, Decisions with Multiple Objectives, John Wiley and Sons, New York, NY, 1976.

Luce, R. D., and H. Raiffa, Games and Decisions, John Wiley and Sons, New York, NY, pp. 25-31, 1957.

Merkhofer, M. W., "Quantifying Judgmental Uncertainty: Methodology, Experiences, and Insights," IEEE Transactions on Systems, Man, and Cybernetics, SHC-17(5), pp. 741-52, September/October 1987.

Raiffa, H., Decision Analysis: Introductory Lectures on Choices Under Uncertainty, Addison-Wesley, Reading, MA, 1968.

Schoner, B. and W. C. Wedley, "Ambiguous Criteria Weights in AHP:

Consequences and Solutions," Decision Sciences, 20, pp. 462-475, 1989.

Spetzler, C. S., and C.-A. S. Stael von Holstein, "Probability Encoding in Decision Analysis," Management Science, 22, pp. 340-58, 1975.

Stael von Holstein, C.-A. S., and J. E. Matheson, 1979, "A Manual for Encoding Probability- Distributions," SRI International, Menlo Park, CA, 1979.

Stokey, E., and R. Zeckhauser, 1978, A Primer for Policy Analysis, Norton, New York, NY, 1978.

Tversky, A., and D. Kahneman, "Judgement Under Uncertainty: Heuristics and Biases," Science, 165, pp. 1232-38, 1974.

Winkler, R. L., "Decision Modeling and Rational Choice: AHP and Utility Theory," Management Science, 36(3), pp. 247-248, 1990.

Zahedi, F., "The Analytic Hierarchy Process--A Survey of the Method and Its Applications," Interfaces, 16(4), pp. 96-108, 1986. 


\section{APPENDIX A \\ RETRIEVAL CONCEPT ACCEPTABILITY CRITERIA}

For developing a methodology and process to evaluate and select retrieval system technologies, the IRG prepared the following set of criteria as an aid based on its overali understanding of the underground storage tank waste retrieval program.

1. Does the retrieval concept appropriately interface with other TWRS program elements?

1.a. Priority resolution of safety issues, including possible in-tank pretreatment.

If retrieval priority was based on resolution of tank safety issues ("Watch List Tanks"--Hydrogen, Ferrocyanide, High Heat Load, and Organic Salts) for Single-Shell Tanks (SSTS), the extent of extensive pretreatment of the retrieved waste would need to be determined, particularly as it relates to the availability of new pretreatment facilities.

As an option, the feasibility and extent of application of in-tank pretreatment would need to be examined for implementation in the period prior to the operation of the pretreatment facility.

1.b. Interim storage capability/requirements.

Without the availability of pretreatment and other downstream facilities, one option is interim storage in existing, if available, or new Double-Shell Tanks (DSTs). However, judgements are necessary to determine DSTs availability for interim storage of retrieved SST wastes, as well as the form of waste (solid or liquid) and their corresponding interim storage volumes.

1.c. Ultimate waste disposition selections.

UTtimate waste disposition options, or waste form and storage/disposal circumstances, may affect retrieval system concepts and technology selection.

1.d. Waste characterization data needs.

Based on current tank characterization strategy and scheduTes, a determination is needed as to when the necessary information to support retrieval technology selection will be available. Also, sufficient tank waste characterization data needs to be obtained to allow for both, regulatory and technical selection criteria, to be employed.

1.e. The waste type/composition impacts.

The various types of tank wastes and their physical composition (over the spectrum of 149 SSTs and 28 DSTs) have an impact on the application candidate retrieval system concepts and technology. 
1.f. Waste conveyance impacts.

In-tank retrieval technology options can impact on the waste conveyance approaches applied to (1) from the underground tank and (2) from the surface confinement structure.

1.g. Infrastructure upgrade requirements.

Based in part on the particular underground tank selected for waste retrieval, the retrieval system can be affected by intertransfer and related infrastructure needs to satisfy upgrade requirements, as well as these support systems for retrieval operations.

2. Does the retrieval concept preclude application of future site closure strategies?

2.a. Soil contamination levels--now and later.

In evaluating retrieval system technologies, it is important to have knowledge of (1) the level of soil contamination that currently exists below and in the vicinity of the tanks, (2) a means to detect additional contamination if it were to occur, (3) expanding potential waste pathways that would be generated by additional ex-tank contamination, and (4) the level of additional soil contamination which might occur if specific types of retrieval systems are implemented.

2.b. In situ remediation (after retrieval) feasibility.

The various in situ remediation options (and their availability) to address different types and levels of waste contamination can impact the selection of retrieval system technologies.

2.c. Further soil contamination control (implies future cleanup).

A key ingredient in controlling the extent of additional soil contamination is through the possible use of barriers external to the tanks. If barriers are demonstrated and accepted as affective contamination control means, they will impact the selection of retrieval system technologies concepts, as well as site closure options and related costs.

2.d. Residual waste and in-tank hardware remaining (technical).

In assessing various retrieval system technologies and how they could fit into an overall SST remediation and closure straceyy, it is important to have a measure of the level to which the tank is to be cleaned (e.g., a possible requirement of removing 95 percent of the waste). Consequently, for site closure it is necessary to know the quantity and characteristics of the wastes that could remain if in-tank hardware, including steel liners, were not removed. 
2.e. Total tank removal requirements.

In addition to understanding the possible impacts of in-place disposal of the SST and associated residual waste on the selection of retrieval technologies, it is important to similarly examine the effects of the technical issues and requirements for removal of the tanks as a site closure option.

3. Are the technology development and implementation schedules acceptable?

3.a. Tri-Party Agreement (TPA) milestone impacts.

The Hanford Federal Facility Agreement and Consent Order (March 1990), commoniy referred to as the Tri-Party Agreement, sets out milestones and criteria which will have impact, now and in the future, on the selection of retrieval system concepts and technologies.

3.b. Accelerated (from TPA) schedule impacts.

Some strategies suggested for Hanford environmental cleanup programs introduce accelerated retrieval schedules relative to the TPA milestones. Such accelerated schedules will impact on the elements of the TWRS, resolution of key safety issues, and availability of retrieval concepts and technologies, as well as affect the schedule interdependence between waste form/characteristics and retrieval.

4. Are costs/budgets required for development and implementation acceptable?

4.a. Mature technologies vs, technologies needing further development (early vs. late schedules and level of development costs).

In evaluating and selecting candidate retrieval system technologies for further development and implementation, it is essential to know the comparative impacts between the possible nearer-term application of mature technologies and those requiring further development. Some of the comparative factors are: cost, development and implementation schedules, risk/benefits, and operational flexibility.

4.b. Application of multiple retrieval systems and larger-scale costs.

To satisfy the challenging schedule of retrieving wastes from the underground tanks in the time allotted by the TPA, it is likely that multiple retrieval systems will need to be employed in parallel. Consequently, cost feasibility and interface impacts of those multiple retrieval systems on other TWRS elements will be an important ingredient in assessing retrieval system concepts and their flexibility in supporting such larger-scale retrieval operations. 
5. Will the retrieval concept and technology gain regulatory and public acceptance?

5.a. Further soil contamination impacts/waste minimization.

In evaluating retrieval technologies which could conceivabiy contribute to further soil contamination, a key issue is public acceptance of additional contamination as a tradeoff with other important factors in technology selection, such as availability of retrieval system, cost, and operational flexibility to meet TPS milestones.

Other related factors are DOE and EPA requirements for waste minimization of secondary waste forms and their application to underground engineered barriers and contaminated soil.

5.b. Residual waste and in-tank hardware.

A key aspect in assessing retrieval technology effectiveness is the final disposition of residual waste and in-tank hardware. (In the EIS decision-making process, requirements could range from a few percent residual to much less.) Further, regulatory requirements would need to be determined for including in-tank hardware and the steel liner as part of the tank disposal and closure process.

5.c. Impact of failed SST.

It may be possible that specific retrieval concepts and technologies and their implementation could have a higher probability of resulting in some structural failure to an SST. In addition to assessing this factor in technology selection, it is important to have an understanding of potential regulatory and public acceptance implications to such a structural failure.

5.d. Interim storage requirements.

Interim storage of processed waste from SSTs (on-site could become an important option if planned off-site repositories are unable to meet the schedules of accommodating these wastes in final disposal form). Regulatory issues and related processes will impact on this application of interim storage. Similarly, regulatory impacts will exist for an interim storage of retrieved waste prior to pretreatment. This second category of interim storage will have a more direct impact on and be impacted by the retrieval system technology used (e.g., different retrieval systems can provide different waste forms and varying resultant volumes for interim storage).

5.e. Existing vs. future technologies and risk/benefits (early vs. later schedules).

One of the key acceptance factors is the determination of the level of acceptance by DOE, regulators and the public for tradeoffs in risk (e.g., a reduced safety risk for early retrieval vs. 
potentially increased risk for additional soil contamination). As part of such tradeoff assessments, the availability of retrieval system technologies for implementation of waste retrieval is a major element.

Another option to consider in developing and applying retrieval technologies is the potential acceptance by TPA stakeholders and regulators of a phased approach to remediating tank waste. For example, from the perspective of several important factors, such as safety and overall costs, it may be effective to field a retrieval technology in a relatively short time frame to retrieve a substantial amount of a tank's waste, with more "finely tuned" and developed technologies retrieving residual wastes to required levels at a later date. A key issue in such a phased approach would be the impact on TPA retrieval milestones.

5.f. Current vs. future regulation impacts.

In the assessment and selection of retrieval system concepts and technologies, it is important to identify and appraise how future trends in environmental, safety, and health rules and regulations could affect and impact technology selections made today. As part of such appraisal, the dimensions of the problem can be reduced by identifying a selected group of regulations which could have the most significant impact on retrieval systems and technologies.

\section{5.g. Total tank removal requirements.}

One option for remediation and closure of the underground tanks is through an in-place disposal of the tank and associated residual wastes. Another option is to retrieve the waste and in-tank hardware and remove the tank for separate disposal. If either option were to be applied, then it would impact on the selection of retrieval technologies to be employed. Consequently, an understanding of the regulatory issues and concerns in applying these options is important to the assessment and selection process for retrieval system technologies.

5.h. Compliance of retrieval system with regulations.

A very important aspect related to regulatory acceptance is the measurement of compliance with existing safety policies and regulations and their impact on the various candidates for retrieval system technology. A key element would be the development of a methodology which would provide a compliance rating (including a measure of regulatory robustness) which would account for (1) existing regulations and (2) major regulatory requirements whose future changes would have significant impact.

6. Will the concept and technology lead to acceptable operability?

6.a. Provides the necessary flexibility and ease of operations.

Evaluating candidate retrieval system technologies for selection has various key elements; one of the most important is that the 
system provides the necessary flexibility and ease of operations while maintaining a high level of safety. Some of the primary factors to be assessed in satisfying necessary operational requirements for the retrieval system technology are:

(1) maintainability, (2) reliability, (3) capacity, and (4) level of complexity (including assessments of cost effectiveness and quantity/size and type of support systems).

7. Will the technology lead to adequate safety?

7.a. Structural integrity (SSTs) requirements.

Based on the age of the SSTs (many over 50 years by time of waste retrieval), periods of exposure to radioactive and hazardous/toxic materials, and relatively high thermal and thermal cycling conditions some of the tanks have experienced, a very important safety condition that needs to be examined is the structural integrity of tanks. First, information (i.e., data, test results, and analysis) needs to be developed on this subject to confirm and appraise the magnitude of this SST safety issue. Other considerations in addressing this safety issue are:

- Identify the base line parameters and descriptive information and data which is necessary to develop criteria for determining SST structural integrity.

- Determine the technologies for assessing the tank structural integrity.

- Identify and examine features of a retrieval system technology that could raise tank structural concerns.

- Identify and examine processes which could have detrimental impact on structural integrity, specifically for SSTs during retrieval operations.

- Identify and assess the possible application of technologies which might alleviate or minimize damage during the waste retrieval process to tanks that may be structurally unsound.

7.b. Retrieval system failure/risk contingencies.

In addition to the very high-priority safety issues for the SSTs (Hydrogen, Ferrocyanide, High Heat Load, and Organic Salts) and the impact of leaking tanks on the evaluation and selection of retrieval system concepts and technologies, there are other safety issues that need $t_{0}$ be considered during such evaluations. For example, what is the potential increase in risk and possible failure of retrieval system equipment, leading to unacceptable consequences, during waste retrieval operations (such as a failed seal between the SST and the surface confinement structure)? Another very significant aspect of such safety evaluations beyond engineering, design, and fabrication of retrieval systems, including features to prevent major failures and their consequences, is contingency planning (e.g., assessing first-order 
failure and effect modes of retrieval systems for an unforeseen structural failure in an SST).

7.c. Safety issues resolution impacts.

Significant factors which will affect the evaluation of retrieval systems are the framework and criteria established for resolving the highest-priority safety issues for the SSTs. For example, the approved criteria for retrieving waste from hydrogen generating tanks will have significant effects on the selection of retrieval systems for such tanks.

7.d. Operational safety criteria impacts.

A major element of assessing retrieval technologies is the level of operational safety provided during waste retrieval. Significant differences in the evaluation rationale for this important factor would exist between retrieval systems that enter through the tank dome and those which would enter through the sidewall or bottom.

7.e. Level of retrieval waste confinement.

During the waste retrieval process, waste conveyed from the tank through the dome and into a surface confinement structure will be governed by an approved level of confinement. The basis and level of this confinement requirement which must be met during retrieval operations can have a significant impact on a retrieval system and its design.

7.f. Mature technologies vs. technologies needing development and risk/benefit (technical).

It is conceivable that an expedited retrieval process using more mature technologies that may be available for nearer term application could provide an earlier resolution of safety issues at lower costs. In evaluating and selecting retrieval system technologies, attention should be given to a comparison of the relative maturity of the technologies, with an assessment of their respective development needs and risk/benefit factors. 